Research Article

\title{
Load Capacities of Steel and Concrete Composite Bridge Deck Slab with Haunch
}

\author{
Xiaoqing $\mathrm{Xu}^{1,2}$ and Yuqing $\mathrm{Liu}^{2}$ \\ ${ }^{1}$ School of Civil Engineering, Chongqing University, Chongqing, China \\ ${ }^{2}$ Department of Bridge Engineering, Tongji University, Shanghai, China \\ Correspondence should be addressed to Yuqing Liu; yql@tongji.edu.cn
}

Received 29 August 2017; Accepted 18 October 2017; Published 24 December 2017

Academic Editor: Luigi Di Sarno

Copyright ( 2017 Xiaoqing Xu and Yuqing Liu. This is an open access article distributed under the Creative Commons Attribution License, which permits unrestricted use, distribution, and reproduction in any medium, provided the original work is properly cited.

An innovative steel and concrete composite bridge deck slab using bent bars and epoxy as shear connectors was proposed. Four slab specimens with different types of concrete were fabricated and tested to study the load capacities of positive and negative moment regions of the slabs. The cracking and ultimate loads of the specimens were recorded and compared with the results calculated through the reinforced concrete theory and with the design load of the bridge deck slab. It was found that reinforced concrete theory can generally be applied for the proposed slab as well. The effectiveness of the shear connector design of the proposed slab was validated. Meanwhile, the unfavourable effect of the haunch on the shear capacities of the positive moment region of steel and concrete composite bridge deck slab was observed.

\section{Introduction}

The steel-concrete composite (SCC) slab has been one of the cost-effective solutions for bridge deck slabs in the past few decades [1]. This type of bridge deck slab requires less amount of supporting girders in the construction site. It is of particular application for use in a long span situation, where the use of RC slabs is not feasible.

To achieve the desired composite action in SCC slab, shear connectors are required to transfer the shear force between steel and concrete members. Thus, they are the important components of steel-concrete members, and the behavior of the composite members such as failure modes, loading capacity, and deformation behavior is significantly affected by the properties of shear connectors. Currently, there are plenty of types of shear connectors available. Although headed studs are the most common type of shear connector, they may be unsuitable for composite slabs because the quality of welding the studs to a thin steel plate is doubtful [2]. Meanwhile, it was reported that premature cracks would occur around the head of the headed stud due to the local stress concentration of concrete $[3,4]$, as shown in Figure 1(a). Recently, application of perforated ribs on composite slabs was reported [5-9]. Though they have large shear capacity and fatigue strength, they may cause potential distresses. As shown in Figure 1(b), premature debonding of the concrete from the steel rib may take place, which accelerates the propagation of fatigue-induced microcracks along the concrete-steel interface. Meanwhile, local stress concentration of concrete around the top flange of the rib is still a critical consideration. Therefore, an effective design of shear connectors is necessary to have better composite slabs.

To examine the effectiveness of the design of shear connectors, tests on the composite slabs are the basic approach. Up to now, most experimental studies focused on the positive moment region of the bridge deck slab. There are much limited experimental data available for behavioral investigation of composite slabs subjected to negative bending. The region of slabs under negative bending such as edge cantilever is under high risk of concrete cracking as it occurs in reinforced concrete (RC) bridge deck slabs. Since the depth of the SCC slab is usually smaller than that of the $\mathrm{RC}$ one, this risk may increase and more attentions are thought to be required. Meanwhile, haunch is often used to enhance the shear strength and flexural strength of the negative moment region of the deck slab. However, the effect 


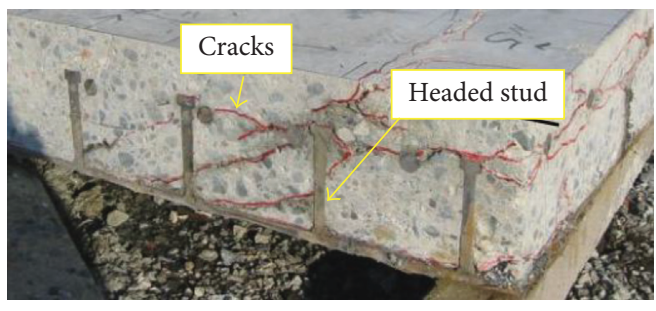

(a)

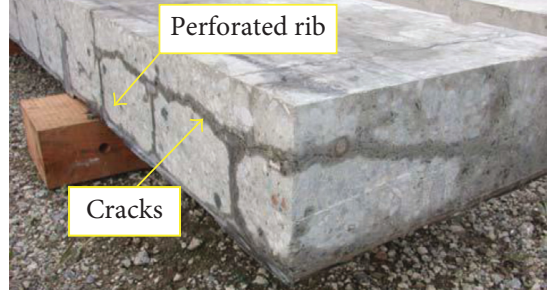

(b)

Figure 1: Premature cracks around the top of the shear connectors. (a) Headed stud [3]. (b) Perforated rib [9].

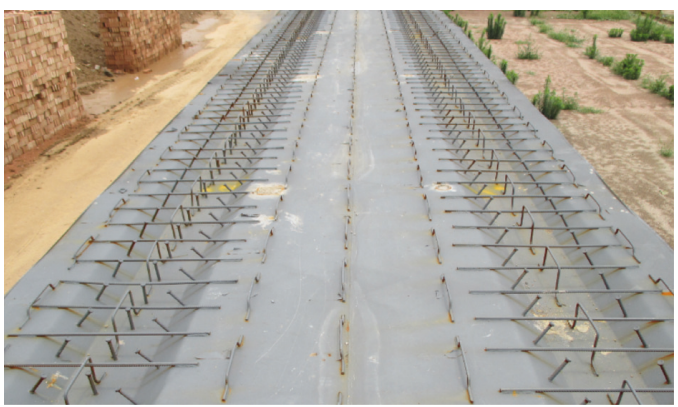

(a)

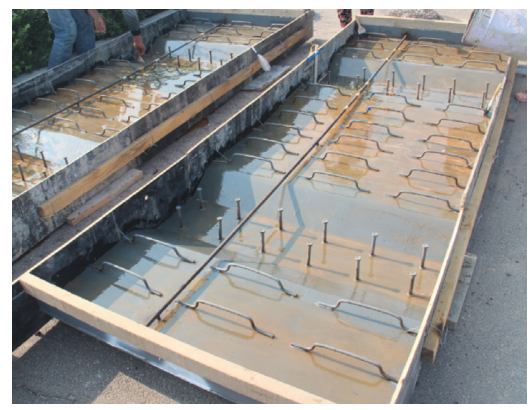

(b)

Figure 2: Steel member of SCC slabs (a) In a real bridge (b) In a test specimen.

of haunch on the behavior of the positive moment region of SCC slab is not clear. Therefore, to examine the effectiveness of the shear connector design, the positive and negative regions of composite slabs with haunch should be tested.

This paper presents an innovative design of steel and concrete composite deck slab which uses bent bars and epoxy as shear connectors. Four SCC slab specimens with haunch were tested to evaluate the load capacities of positive and negative moment regions of the proposed composite bridge deck slabs. Failure processes of the specimens were recorded, and attention was addressed to the effectiveness of the shear connector design. The experimental results are compared to the design codes of RC slabs, which would contribute to develop the design codes for SCC slab in the future.

\section{Design and Application of the Proposed Deck Slab}

Figure 2 shows photos of the steel member of the SCC bridge deck slab proposed in this study. The SCC bridge deck slab consists of profiled steel sheeting, steel reinforcements, concrete, bent bars, and epoxy. A unique feature of the proposed SCC slab is that bent bars and epoxy are used as shear connectors to resist the shear forces between steel sheeting and concrete slab. The anchorage of bent bars in concrete is provided by bond forces at the interface between steel and concrete. Thus, local stress concentration of concrete can be avoided in SCC slab with bent bars. Meanwhile, since the diameter of the bent bar used in this study is not larger than 2 times of the thickness of the steel plate, the welding quality can be well controlled according to the study by [1]. Therefore, when comparing with headed studs, bent bars are expected to improve the fatigue behavior of SCC slab. When comparing with perforated steel ribs, bent bars would not weaken the section of SCC slab in the longitudinal direction, which can avoid premature cracking of the concrete in this direction. Meanwhile, the material and welding cost of bent bars is much lower than that of perforated steel ribs. Besides the bent bars welded on the steel plate, epoxy is sprayed onto the surface of the steel sheeting in order to improve the interfacial behavior between steel and concrete.

As shown in Figure 3, this type of bridge deck slab has already been applied to one steel and concrete composite bridge in China [10]. Figure 4 shows the slab in detail. The slab has a clear transverse span length of $1700 \mathrm{~mm}$ with a total length of $3360 \mathrm{~mm}$. Its longitudinal span length is $6000 \mathrm{~mm}$, which is larger than 2 times of its transverse span length. As a result, the slab was treated as a one-way slab in this study.

The steel plate was profiled to form the bottom sheeting with a $100 \mathrm{~mm}$ high haunch. A thickness of $6 \mathrm{~mm}$ was adopted in order to assure the welding quality. The concrete cover on the bottom is not required in SCC slab, so the thickness of concrete slab was designed to be $150 \mathrm{~mm}$ which is smaller than that of traditional RC bridge deck slab. Moreover, headed studs are arranged near the support to transfer the shear forces between SCC bridge deck slab and bridge girders. Steel bars of $10 \mathrm{~mm}$ diameter are placed at a spacing of $100 \mathrm{~mm}$ in both transversal and longitudinal directions forming two layers of the steel bar mesh, which are designed to resist the bending moment in two directions and control cracking. 


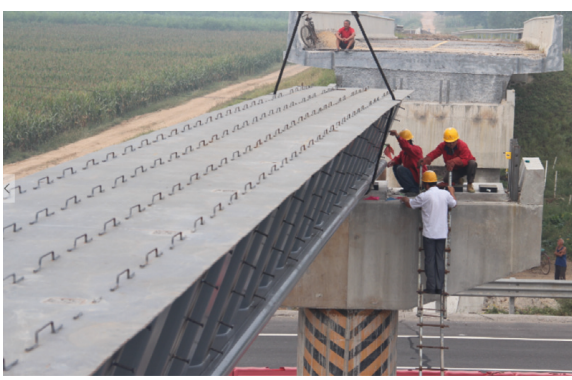

(a)

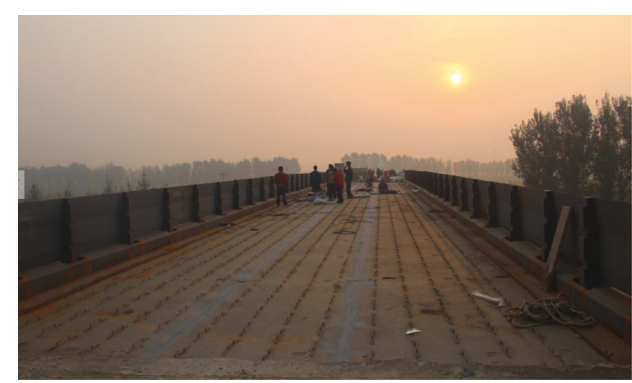

(b)

FIGURE 3: (a) Fabrication of one bridge girder with the proposed deck slab (b) Welding the steel members of the proposed deck slab.

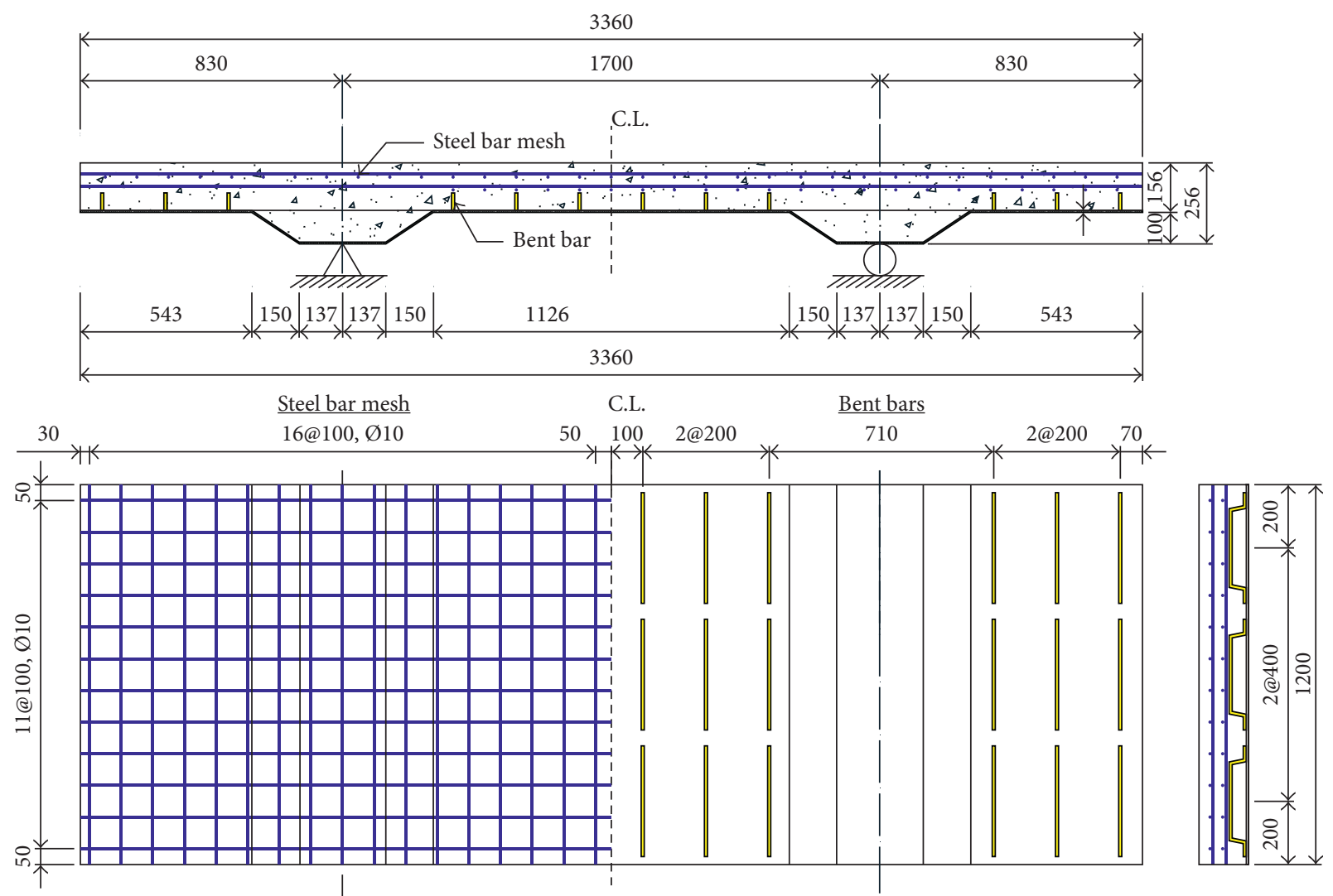

FIGURE 4: Details of the SCC bridge deck slab.

The SCC bridge deck slab uses bent bars and epoxy as shear connectors to transfer the shear forces at the interface of concrete and steel plate. The arrangement of these shear connectors should ensure the interface has sufficient shear strength to resist the shear forces. For the slab section with unit width under the vertical shear load $P$, the shear force carried by one shear connector at the interface $V_{\text {sd }}$ can be calculated through (1).

$$
V_{\mathrm{sd}}=\frac{P Q_{\mathrm{s}}}{I_{0} b} p \frac{1}{n}
$$

where $Q_{\mathrm{s}}$ is the first moment of the steel plate; $I_{0}$ is the moment inertia of the slab section; $b$ is the unit width; $p$ is the spacing of the shear connector in the longitudinal direction of the slab; and $n$ is the number of shear connectors in the transversal direction of the slab. Then, the combined shear strength of bent bars and epoxy should be larger than $V_{\text {sd }}$.

$$
V_{\text {sd }} \leq V_{\text {ss, b }}+V_{\text {ss,e }},
$$

where $V_{\mathrm{ss}, \mathrm{b}}$ and $V_{\mathrm{ss}, \mathrm{e}}$ are the shear strength of bent bars and epoxy, respectively.

Figure 5 shows the bent bars which were made from $10 \mathrm{~mm}$ diameter rolled plain steel bars. The shear strength of the bent bar can be obtained through (3).

$$
V_{\mathrm{ss}, \mathrm{b}}=A_{\mathrm{s}, \mathrm{b}} f_{\mathrm{s}, \mathrm{d}},
$$

where $V_{\mathrm{ss}, \mathrm{b}}$ is the shear strength of one bent bar; $A_{\mathrm{s}, \mathrm{b}}$ is the section area of the bent bar; and $f_{\mathrm{s}, \mathrm{b}}$ is the design strength of the steel material. The epoxy applied on the surface of the 


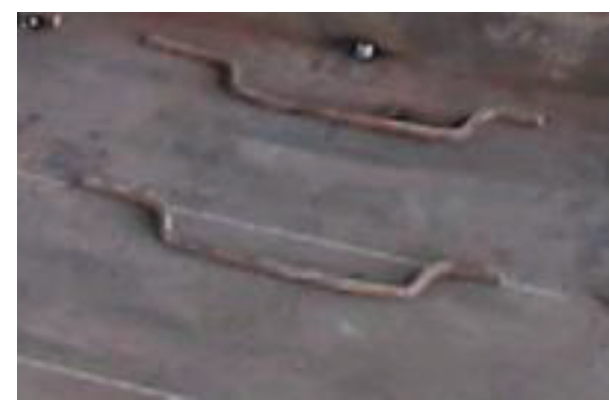

Figure 5: Bent bars.

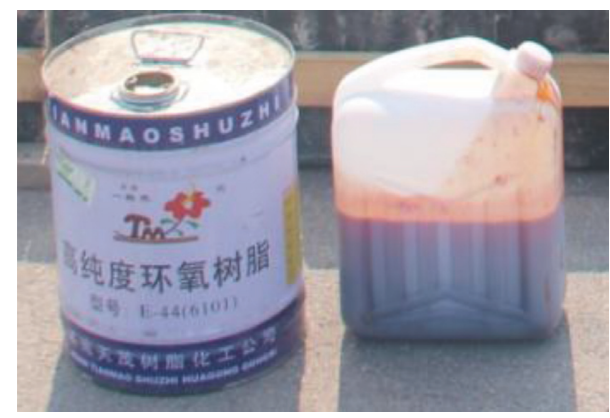

Figure 6: Epoxy.

TABLE 1: Summary of test specimens.

\begin{tabular}{lcc}
\hline Specimen label & Concrete type & Region \\
\hline P1 & PMC & Positive moment region \\
P2 & OC & \\
\hline N1 & PMC & Negative moment region \\
N2 & OC & \\
\hline
\end{tabular}

steel plate is shown in Figure 6. The engineering properties of the epoxy were provided by the manufacturer. The epoxy can provide the bond between concrete and steel of the normal strength of $3.0 \mathrm{MPa}$ and shear strength of $12.0 \mathrm{MPa}$ at normal temperature. Based on the equations above, the bent bars were placed at a spacing of $200 \mathrm{~mm}$ in the transversal direction and $400 \mathrm{~mm}$ in the longitudinal one.

\section{Experiment Program}

Totally 4 bridge deck slab specimens were discussed as summarized in Table 1. The characters " $\mathrm{P}$ " and "N" stand for positive and negative moment regions, respectively. P1 and P2 had configurations of single span with two edge cantilevers. The rest of the specimens were half of the former ones. Two types of concrete were used. One is polymer-modified concrete (PMC), and the other is ordinary concrete (OC). In order to evaluate the effects of both compressive strength and tensile strength of concrete on the behavior of SCC bridge deck slab, the PMC composite was carefully designed in order that PMC has smaller concrete compressive strength but larger concrete tensile strength than OC. Structural behaviors of the slabs as indicated by displacement, local strain, and cracking of specimens were chiefly focused on.

3.1. Tests on Positive Moment Region. Two full-scale SCC bridge deck slab specimens with $1200 \mathrm{~mm}$ width were loaded in four-point bending tests. As shown in Figure 7, a $2000 \mathrm{kN}$ loading device was used to apply a concentric load on the distributive beam, and the value of the load was measured by a load cell. The load was distributed to the slab through rods of $100 \mathrm{~mm}$ diameter and steel plates of $20 \mathrm{~mm}$ thickness, which resulted in two-line loads of the same width of the specimen. A shear span of $600 \mathrm{~mm}$ was adopted. Steel rods of $100 \mathrm{~mm}$ diameter were placed between two steel plates to obtain simple support condition. The loading program for two specimens was similar. The first loading and unloading cycle with the maximum load larger than the cracking load was applied under load control after the preloading. Then, the specimens were loaded to fail under displacement control.

3.2. Tests on Negative Moment Region. As shown in Figure 8, the specimens tested in cantilever tests were fabricated as half of those in the four-point bending tests. The tests had the similar loading program. As shown in Figure 9, a $500 \mathrm{kN}$ loading device was used to apply a point load on a steel girder, which resulted in a line load on the left side of the specimen and $700 \mathrm{~mm}$ away from the support, while the right side of the specimen was fixed by a steel frame. Displacement control was used, and the test was terminated when either the maximum stroke of the jack was reached or the displacement of specimen increased significantly.

3.3. Instrumentations. All the specimens were similarly instrumented. Strain gauges were mounted on the steel bars and steel plates and surfaces of the concrete blocks at three critical sections of the specimens. As shown in Figure 10(a), in P1 and P2 specimens, the three sections are near the support (Section A), at the shear span (Section B), and at the midspan (Section $\mathrm{C}$ ), respectively. In $\mathrm{N} 1$ and $\mathrm{N} 2$ specimens, they are near the loading plate (Section A), at the shear span (Section B), and at the support (Section C), respectively, as shown in Figure 10(b). Specially, in order to study the behavior of the bent bars, strain gauges were mounted on the bars as shown in Figure 11.

Crack width was also recorded by the crack observation device with the accuracy of $0.01 \mathrm{~mm}$. The crack patterns earned were also drawn. Displacement transducers were arranged to measure vertical displacements along the specimens. All the measurement transducers except the crack measurement device were connected to a data acquisition device.

3.4. Materials. The reinforcement bars of $10 \mathrm{~mm}$ diameter are HRB400E steel bars with a guaranteed yield strength of $400 \mathrm{MPa}$, and the actual yield strength and tensile strength were tested to be $450 \mathrm{MPa}$ and $650 \mathrm{MPa}$, respectively. Meanwhile, HPB300 steel bars were used for bent bar shear connectors with a yield strength of about $420 \mathrm{MPa}$. The steel 


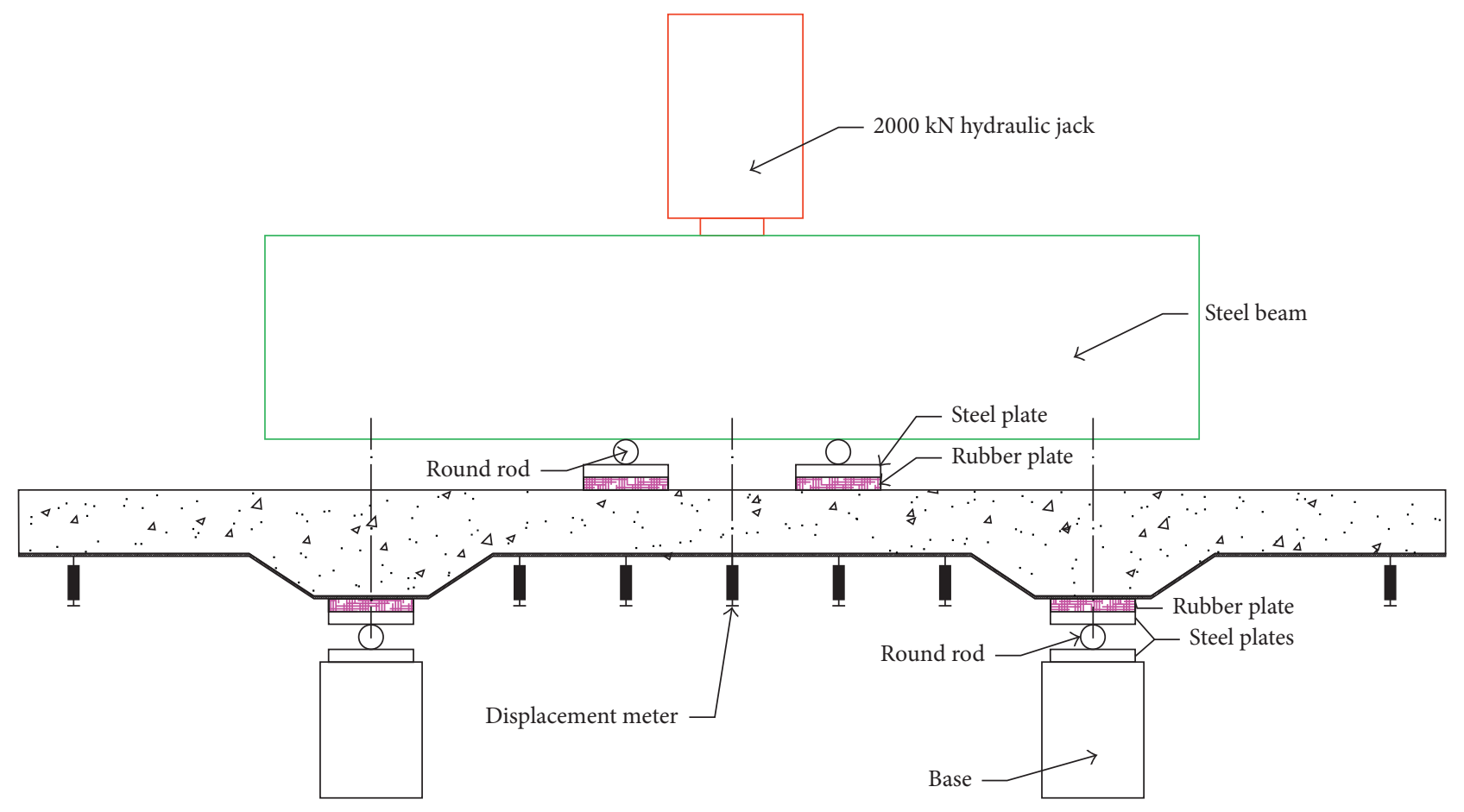

FIgURE 7: Setup for four-point bending tests.

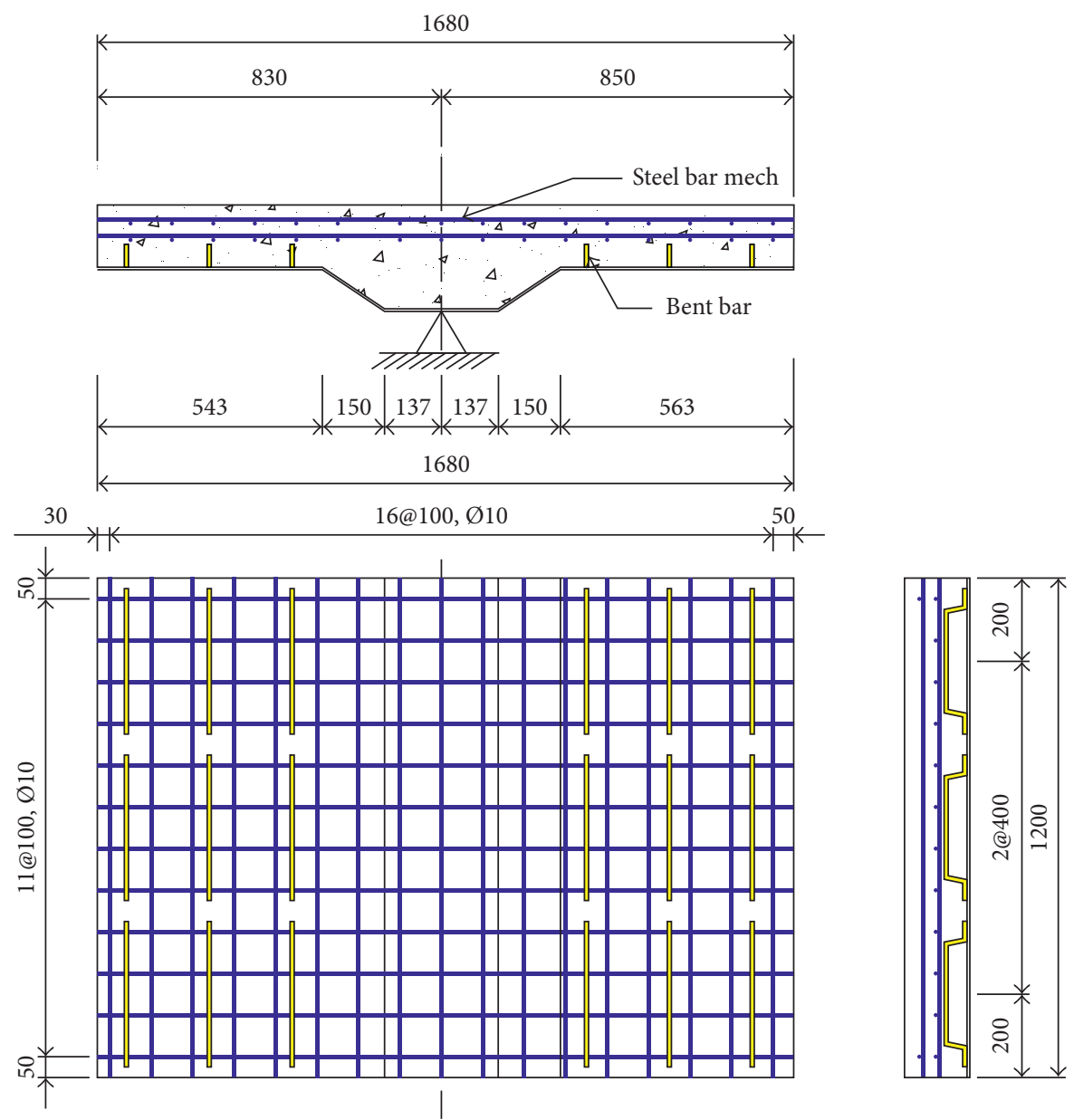

Figure 8: Details of specimens for tests on negative moment region. 


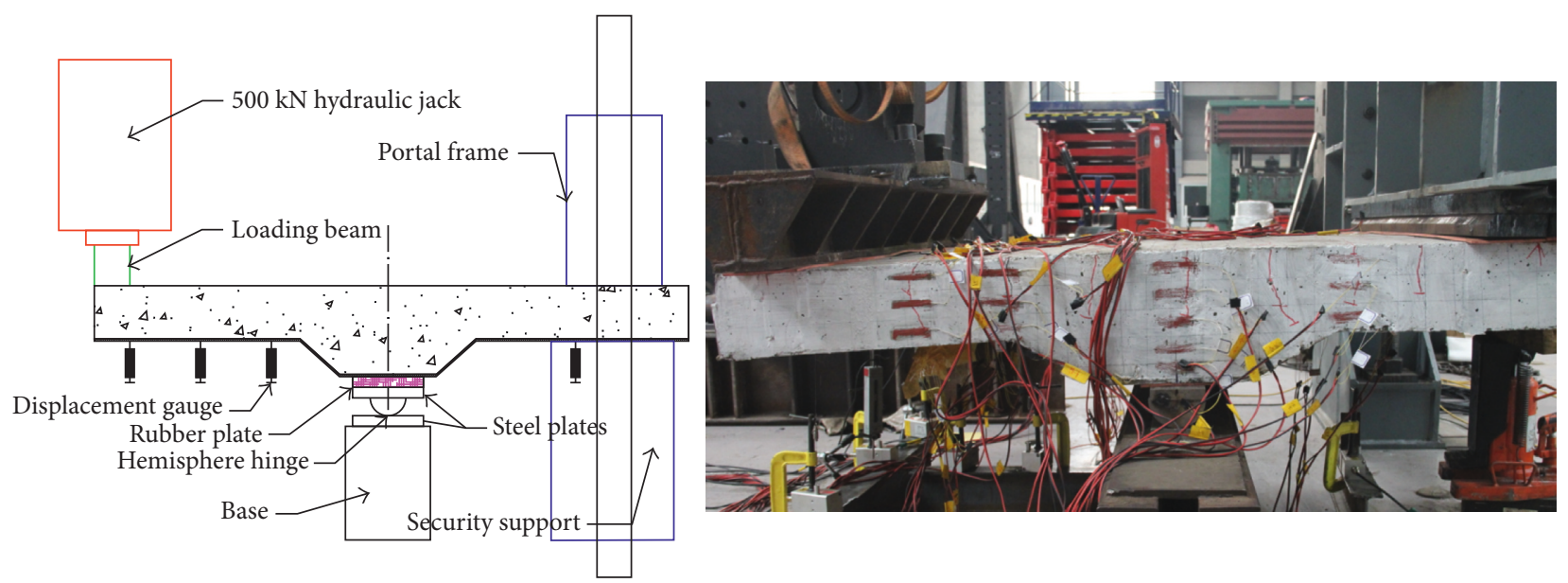

FIgURE 9: Setup for cantilever tests.

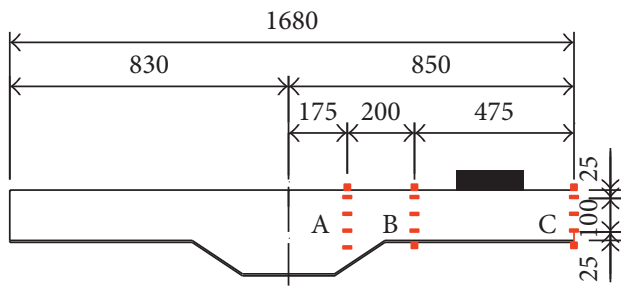

Side surface

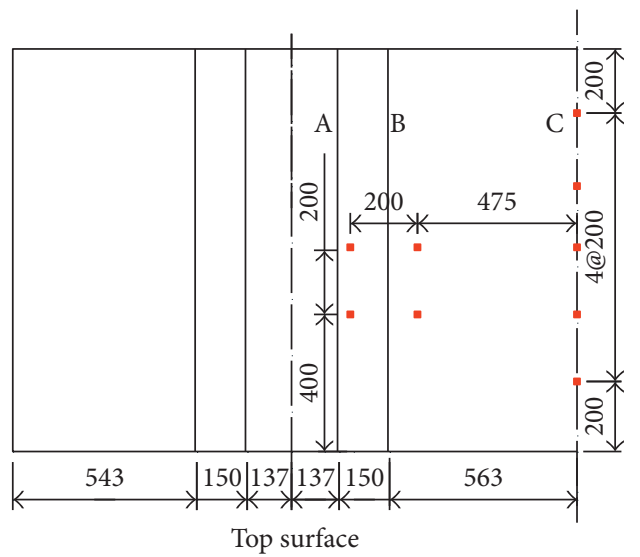

(a)

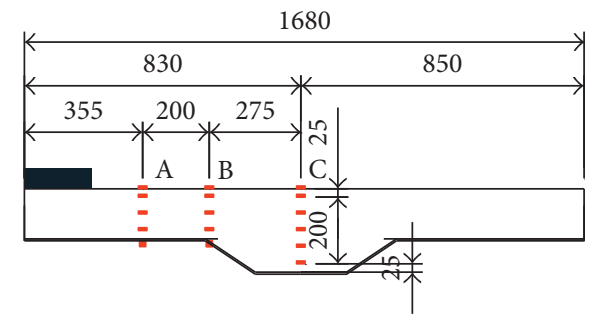

Side surface

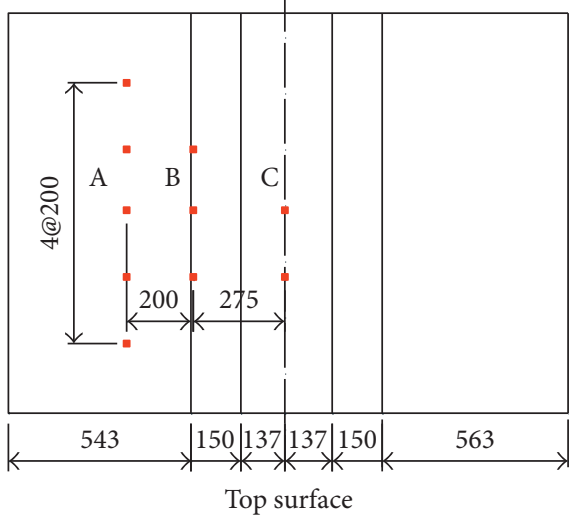

(b)

Figure 10: Arrangement of strain gauges on the concrete surface. (a) P1 and P2. (b) N1 and N2.

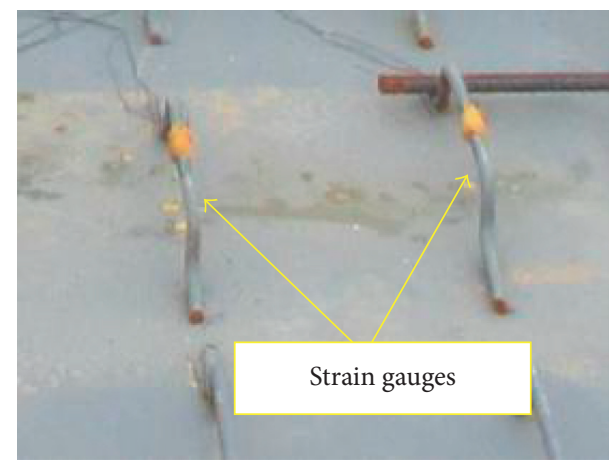

FiguRE 11: Strain gauges on the bent bars. plates and ribs are made of weathering steel Q355qENH with a tensile yielding stress of $400 \mathrm{MPa}$ and an ultimate stress of $540 \mathrm{MPa}$.

Ordinary concrete of grade $\mathrm{C} 45$, which is often used in bridge design, was chosen for two of the specimens. Polymer-mixed concrete composite was applied to the other two specimens. The mix proportions of concrete were listed in Table 2. The photos of the material used were presented in Figure 12. Table 3 shows the material properties of these concrete composites which were tested on the day when the tests on bridge slabs were conducted. Compared with ordinary concrete, PMC has smaller cubic compressive strength $\left(f_{\mathrm{cu}}\right)$ and Young's modulus $\left(E_{\mathrm{c}}\right)$, and larger flexural 
TABLE 2: Mix proportions of concrete $\left(\mathrm{kg} / \mathrm{m}^{3}\right)$.

\begin{tabular}{lccccccc}
\hline Concrete type & Cement & Water & Sand & Stone & Fly ash & Basalt fiber & EVA latex \\
\hline PMC & 496 & 156.8 & 646 & 1055 & 55 & 4 & 66.12 \\
OC & 390 & 192 & 677 & 890 & 133 & - \\
\hline
\end{tabular}

TABLe 3: Material properties of concrete.

\begin{tabular}{lccccc}
\hline Concrete type & $f_{\mathrm{cu}}(\mathrm{MPa})$ & $f_{\mathrm{c}}^{\prime}(\mathrm{MPa})$ & $f_{\mathrm{ct}, \mathrm{fl}}(\mathrm{MPa})$ & $f_{\mathrm{ct}}(\mathrm{MPa})$ & 4.1 \\
\hline PMC & 41.5 & 33.5 & 6.1 & $E_{\mathrm{c}}(\mathrm{GPa})$ \\
OC & 51.1 & 41.1 & 5.5 & 3.7 & 23.9 \\
\hline
\end{tabular}

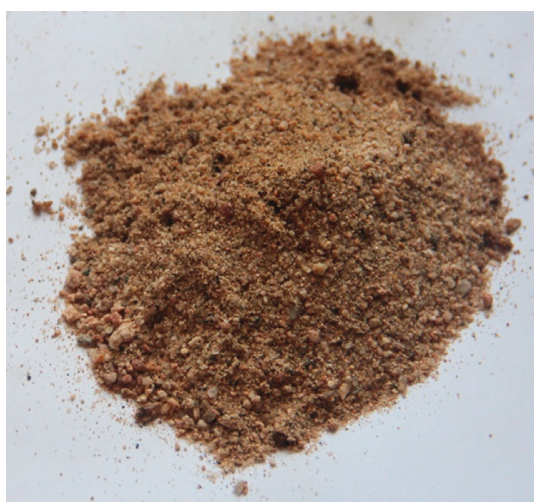

(a)

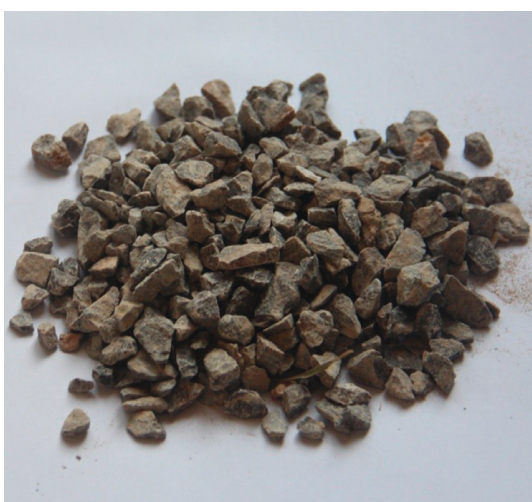

(b)

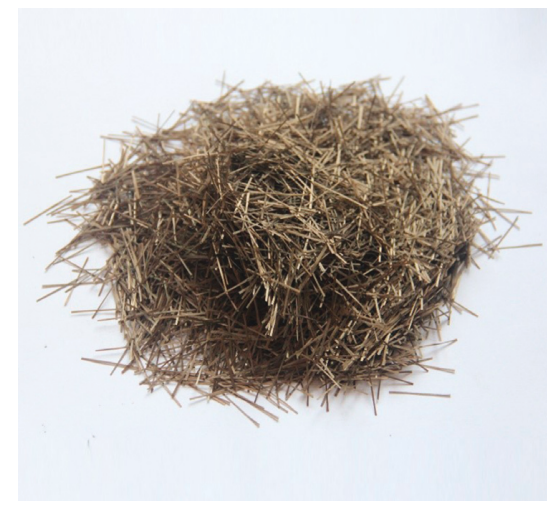

(c)

FIgURe 12: Photos of sand, aggregate, and basalt fiber used in concrete. (a) Sand. (b) Aggregate. (c) Basalt fiber.

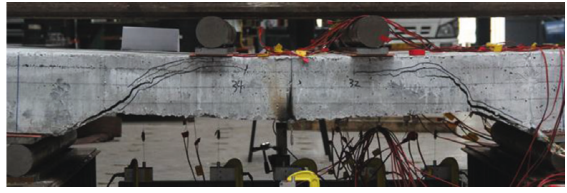

(a)

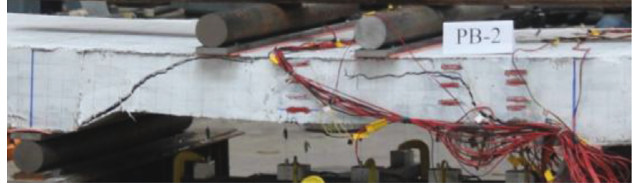

(b)

Figure 13: Failure modes of (a) P1 and (b) P2 specimens.

strength $\left(f_{\mathrm{ct} f \mathrm{ff}}\right)$. The concrete tensile strength $\left(f_{\mathrm{ct}}\right)$ and cylindrical compressive strength $\left(f_{c}^{\prime}\right)$ were calculated through FIB Model Code 2010 [11].

\section{Results and Discussion of Tests on Positive Moment Region}

\subsection{Test Results}

4.1.1. Failure Modes. Figure 13 shows the failure modes of the test specimens. In both specimens, cracks initiated from the top of haunch. The initial crack occurred suddenly and induced debonding of the steel plate from concrete slab at the haunch. Accompanying the crack propagating to the load point and the crack increasing width, debonding was observed at the bottom of haunch. Finally, the specimens failed mainly in the mode of shear compression. An arch is thought to be formed on the upper part of the major crack. This arch represents the compression strut in view of strut-tie modeling.
Meanwhile, the steel plate in tension works as a tension cord, which was anchored at the extreme ends.

4.1.2. Load-Displacement Relationship. The deflection variation along the longitudinal direction under different loading levels is presented in Figure 14. After the shear cracks occurred, the side of the slab where shear cracks occurred would have larger deformation. The shear deformation near the two supports was much larger than the midspan flexural deformation.

The load-displacement curves of P1 and P2 specimens with different types of concrete are compared as shown in Figure 15. The curves have a sudden decrease in stiffness after the linear elastic zone up to about $300 \mathrm{kN}$, and visible shear cracks appeared subsequently. The shear cracking loads for two specimens were similar. Then, both specimens underwent postcracking inelastic deformation. Table 4 summarized the cracking load and ultimate load. The load capacity of P2 specimen was about 1.5 times of that of P1 


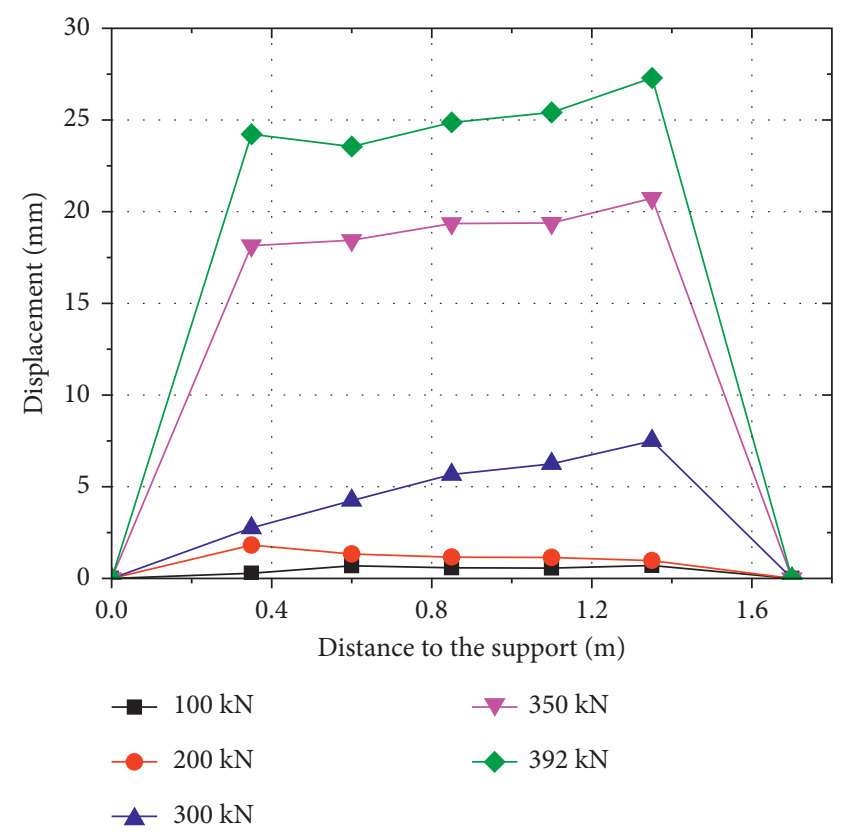

(a)

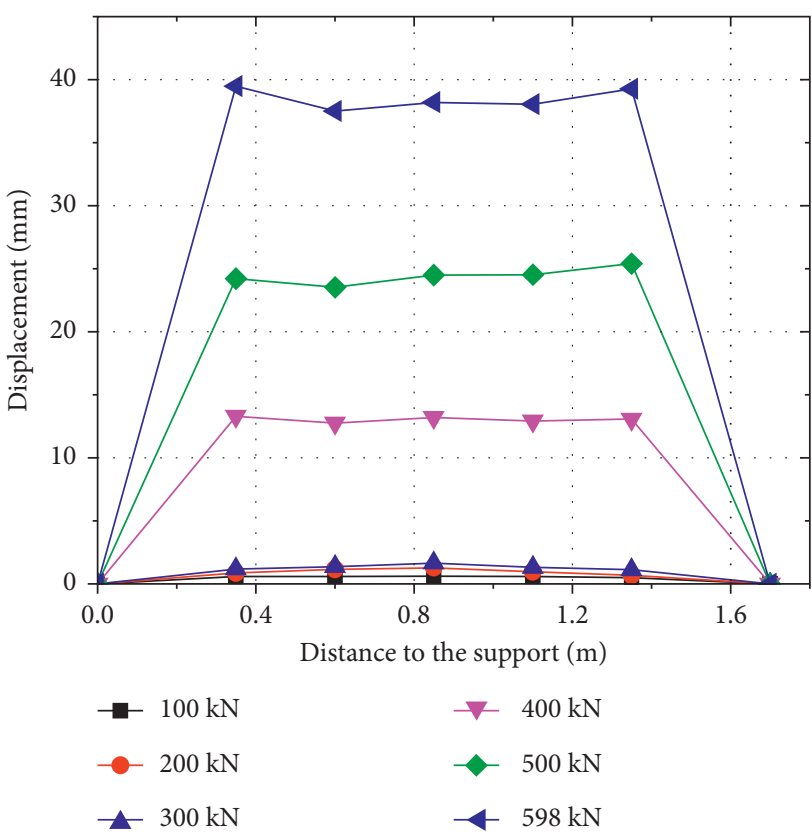

(b)

FIGURE 14: Deflection along the longitudinal direction of the specimens. (a) P1. (b) P2.

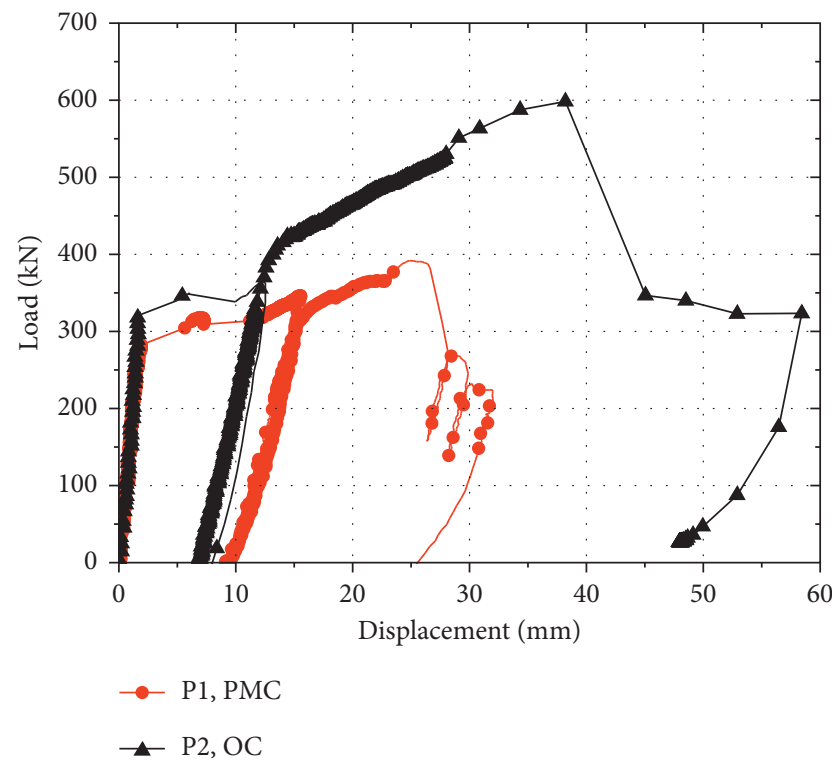

Figure 15: Load-displacement curves of P1 and P2 specimens.

specimen. The displacement of P2 at the ultimate load was $38.2 \mathrm{~mm}$, while the displacement of P1 was $26.1 \mathrm{~mm}$. It implies the higher ductility of $\mathrm{P} 2$, which means that, in $\mathrm{P} 2$, more energy was consumed before failure than that in P1.

4.1.3. Strain Results. The longitudinal strains at Section C of P1 and P2 specimens are depicted along the height of the slab, as shown in Figure 16, in which the longitudinal strains on the top and bottom were the results of strain gauges located at the center of the cross section. It can be found that before the shear cracks occurred, the section almost remained plane after bending. However, after shear cracking, the concrete compressive strains increased rapidly. When the specimens failed, the concrete compressive strains were under $1500 \mu \varepsilon$ and the strains of steel plates reached about $400 \mu \varepsilon$, which were smaller than the failure strains of concrete and steel materials. Therefore, Section C did not reach its flexural capacity, and the specimens did not fail in bending.

In order to show the failure process of the specimen, strain results during the first loading cycle of the sections (Section B) across the main shear crack of P1 and P2 specimens were plotted against the displacement at the midspan section in Figure 17. Results of strain gauges from top to bottom of the slabs are sequentially plotted, among which no. 12 and no. 8 gauges were on the steel plate. Two distinct stages were observed before and after shear cracking. For both specimens, the first stage was characterized by the linear and synchronous increase in strain values of these strain gauges. As a result, cross section remained plane in this stage, and the beam action predominated. At the second stage, for P1 specimen, a sudden increase in the compressive strain was observed while the tensile strain almost remained unchanged. It indicates that stress in this section was rapidly redistributed and arch action came to the reality. Different from the behavior of P1 specimen, strains of P2 specimen almost remained unchanged until a slight adjustment happened at the displacement of $6 \mathrm{~mm}$. This more ductile behavior after shear cracking in P2 specimen is consistent with the findings in load-displacement curves.

The results of strain gauges on three bent bars of P2 specimen are shown in Figure 18. No. 51, no. 52, and no. 53 strain gauges were on the bent bars $35 \mathrm{~cm}, 55 \mathrm{~cm}$, and $75 \mathrm{~cm}$ away from the support, respectively. When the load was smaller than $180 \mathrm{kN}$, the strains of all the bent bars almost 
TABle 4: Comparison of experimental results with the design load and calculated results.

\begin{tabular}{ccccccccccccc}
\hline & \multicolumn{2}{c}{$\begin{array}{c}\text { Experimental } \\
\text { results }\end{array}$} & & \multicolumn{2}{c}{ Design load } & \multicolumn{3}{c}{$\begin{array}{c}\text { Comparison } \\
\text { with design load }\end{array}$} & \multicolumn{2}{c}{ Calculated results } & \multicolumn{2}{c}{$\begin{array}{c}\text { Comparison with } \\
\text { calculated results }\end{array}$} \\
& $V_{\mathrm{cr}}(\mathrm{kN})$ & $V_{\mathrm{u}}(\mathrm{kN})$ & $M_{\mathrm{d}}(\mathrm{kN} \cdot \mathrm{m})$ & $V_{\mathrm{d}, \mathrm{fl}}(\mathrm{kN})$ & $V_{\mathrm{d}, \mathrm{s}}(\mathrm{kN})$ & $V_{\mathrm{cr}} / V_{\mathrm{d}, \mathrm{s}}$ & $V_{\mathrm{u}} / V_{\mathrm{d}, \mathrm{s}}$ & $V_{\mathrm{cr}, \mathrm{CAL}}(\mathrm{kN})$ & $V_{\mathrm{u}, \mathrm{CAL}}(\mathrm{kN})$ & $V_{\mathrm{cr}, \mathrm{CAL}} / V_{\mathrm{cr}}$ & $V_{\mathrm{u}, \mathrm{CAL}} / V_{\mathrm{u}}$ \\
\hline $\mathrm{P} 1$ & 320 & 392.03 & \multirow{2}{*}{32.6} & \multirow{2}{*}{108.8} & \multirow{2}{*}{166.8} & 1.91 & 2.35 & 351.5 & 434.6 & 1.10 \\
$\mathrm{P} 2$ & 365 & 598.40 & & & & & 2.19 & 3.59 & 307.3 & 508.1 & 0.84 & 0.85 \\
\hline
\end{tabular}

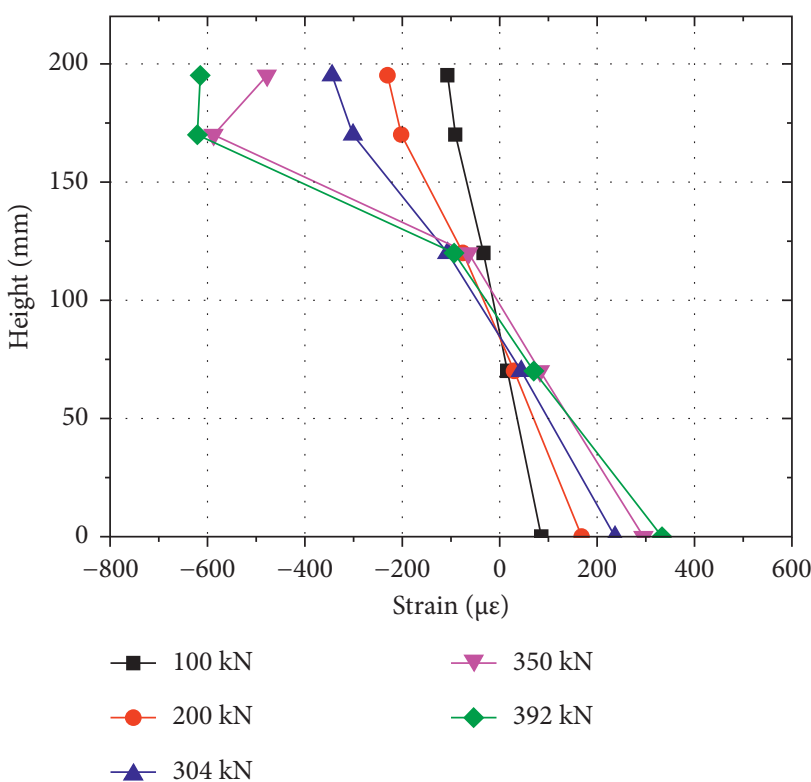

(a)

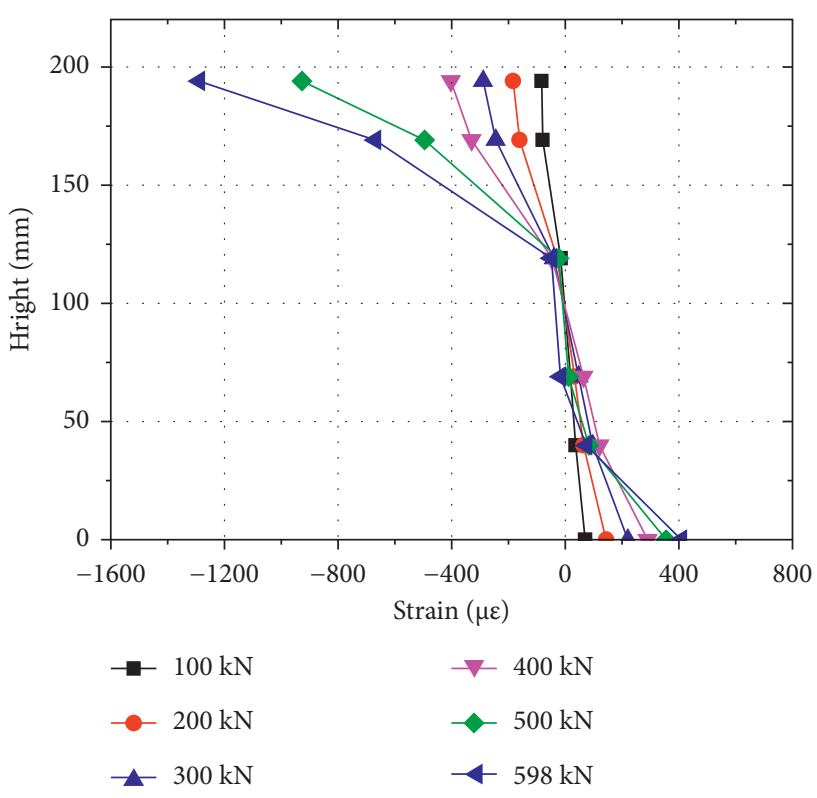

(b)

Figure 16: Longitudinal strain distribution along the height at Section C. (a) P1. (b) P2.

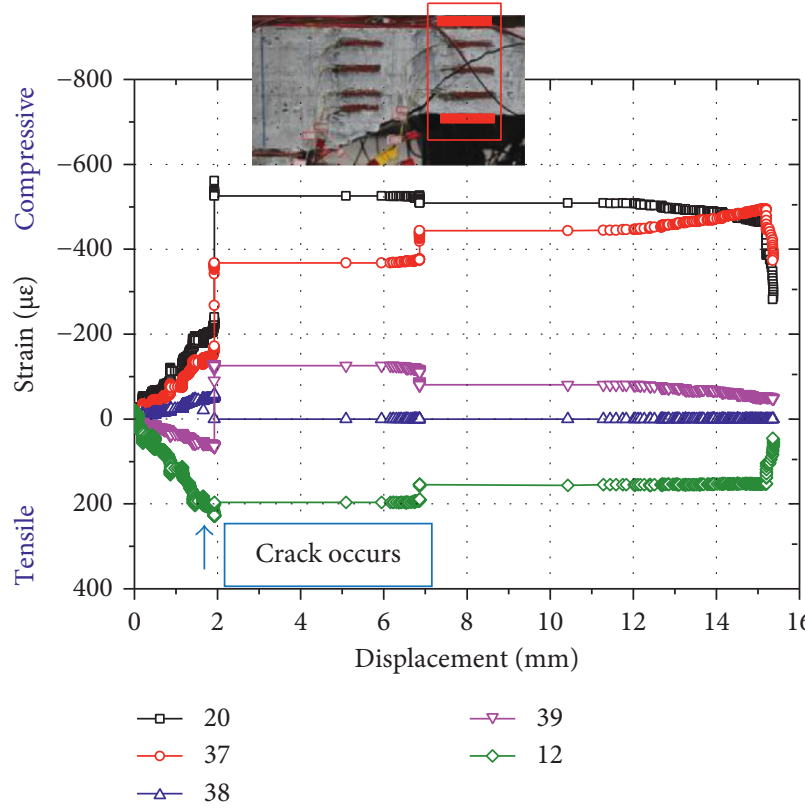

(a)

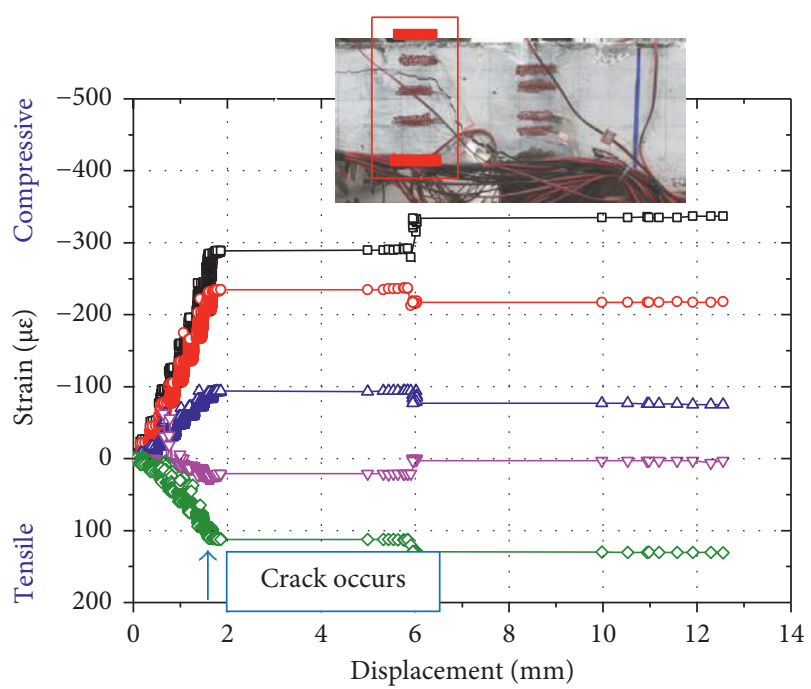

$$
\begin{array}{ll}
\rightarrow-28 & \rightarrow-42 \\
\multimap-40 & \multimap-8 \\
\rightarrow-41 &
\end{array}
$$

(b)

Figure 17: Strain results of P1 and P2 specimens under different displacements at Section B. (a) P1. (b) P2. 


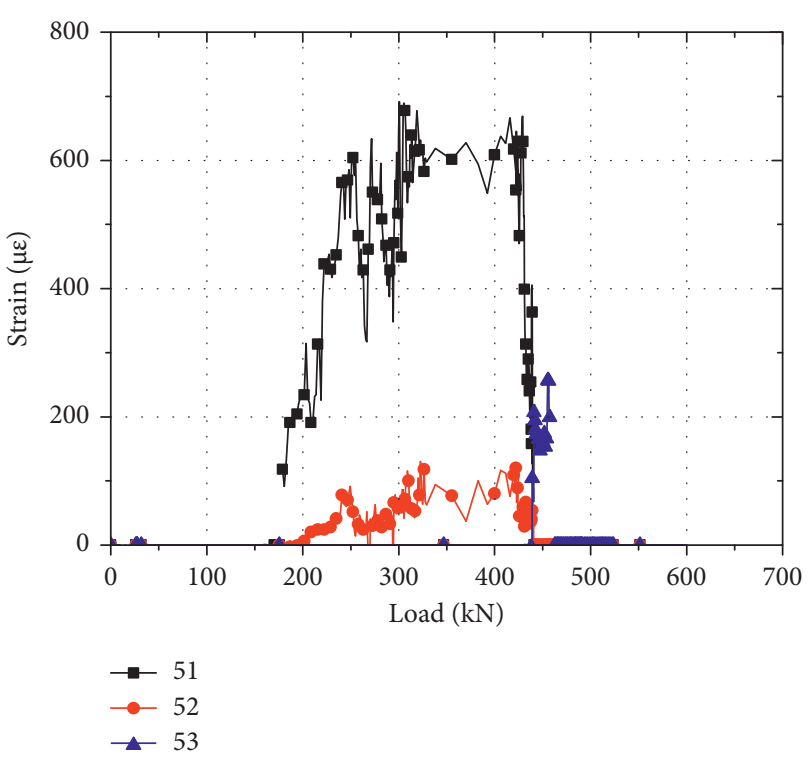

Figure 18: The strain results of bent bars in P2 specimen.

remained zero. As the shear force resisted by the bent bar is proportional to the relative slip, it indicates that the relative slip was negligible at the low-load stage because epoxy has very large shear stiffness. Then, the strains of no. 51 and no. 52 gauges increased with the load, and the closer the bent bar to the support, the larger the strain would be. Therefore, the relative slip near the support was the largest. Meanwhile, the bent bar at the pure bending region had the smallest strain, which means that full composite action between the steel plate and concrete slab was achieved.

\subsection{Capacity Calculation}

4.2.1. Shear Cracking Load. In P1 and P2 specimens, shear cracks initiated at stress concentration points where the stress states were complicated. However, since the specimens were at a low-stress state before shear cracking, it is reasonable to assume that steel and concrete materials were in elastic condition. Based on this assumption, the shear stress and tensile stress due to shear load and bending moment were calculated to get the principal tensile stress at the critical point [12].

$$
\begin{gathered}
\sigma_{1}=\frac{\sigma_{\mathrm{x}}}{2}+\sqrt{\left(\frac{\sigma_{\mathrm{x}}}{2}\right)^{2}+\tau_{\mathrm{xy}}} . \\
\sigma_{\mathrm{x}}=\frac{M}{I_{0}}, \\
\tau_{\mathrm{xy}}=\frac{V_{\mathrm{cr}}}{A_{0}},
\end{gathered}
$$

where $\sigma_{1}$ is the principal tensile stress; $\sigma_{\mathrm{x}}$ and $\tau_{\mathrm{xy}}$ are the normal stress and shear stress, respectively; $M$ is the bending moment of the section; $V_{\mathrm{cr}}$ is the shear cracking load; $A_{0}$ is the area of the section which includes the area of steel bars and plates which is transformed into an equivalent concrete

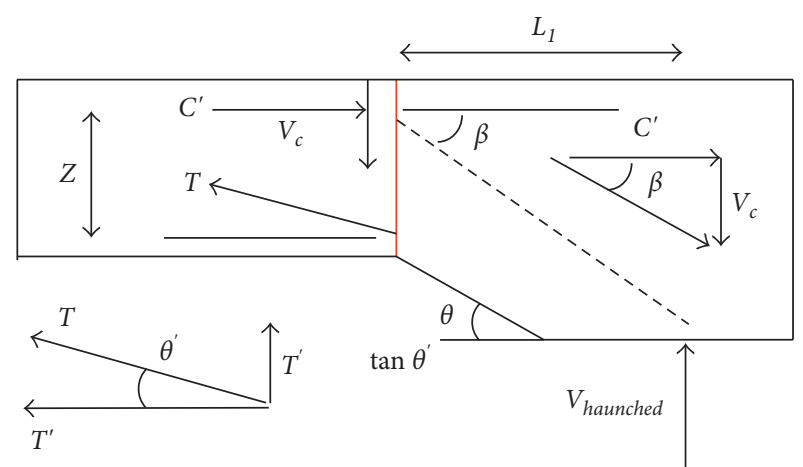

FIGURE 19: Forces in slabs with haunch.

member; $I_{0}$ is the moment inertia of the section; and $y$ is the distance from the neutral axis to the bottom tensile fiber of concrete. Stress components at the critical point were calculated, and the shear stress is only $10 \%$ of the normal stress. Normal stress has greater contribution to the principal tensile stress. Then, the shear cracking load was calculated based on the principle that shear cracking occurs when the principal tensile stress is equal to the concrete's tensile strength.

$$
\sigma_{1}=f_{\mathrm{ct}}
$$

4.2.2. Shear Strength. Haunch is one of the main characteristics of the composite slabs tested. For a reinforcement concrete member, it is believed that the ultimate shear capacity of the RC member is a function of the haunched angle because of the inclination of the tensile resultants due to the haunch [13]. As shown in Figure 19, the tensile force is inclined and introduces a component transverse to the axis of the member. Then, the shear capacity of the specimen is equal to

$$
V_{\text {haunched }}=V_{c}-T \sin \theta=V_{c}-T^{\prime} \tan \theta
$$

Since $\tan \theta^{\prime}$ and $M=V_{\text {haunched }} L_{1}$, then

$$
V_{\text {haunched }}=V_{c}-\frac{V_{\text {haunched }} L_{1}}{Z} \tan \theta^{\prime}
$$

where $V_{\text {haunched }}$ is the shear strength of haunched slab; $V_{c}$ is the shear strength of prismatic slab with the same effective depth with the critical section; $T$ is the tension force in the steel plate; $\theta$ is the angle of the slope of haunch from horizontal; $\theta^{\prime}$ is the angle of the slope of $T$ from horizontal; $T^{\prime}$ is the vertical component of $T$ which contributes to the external shear force; $Z$ is the level arm of the section, and $Z=0.8 d$ was assumed; $d$ is the effective height of the section; and $L_{1}$ is the distance between the support and the critical section.

Instead of the original geometrical angle of haunch from horizontal, the angle of the steel plate from horizontal at the ultimate load was used as $\theta^{\prime}$, which is smaller than the original one due to the separation between the steel plate and concrete slab as shown in Figure 13. Then, $V_{c}$ was calculated according to the procedure given in the JSCE standard [14], 
TABLE 5: Calculation of the shear strength.

\begin{tabular}{ccccccc}
\hline & $\begin{array}{c}d \\
\mathrm{~mm}\end{array}$ & $\begin{array}{c}L_{1} \\
\mathrm{~mm}\end{array}$ & $\tan \theta^{\prime}$ & $\begin{array}{c}V_{\mathrm{c}} \\
\mathrm{kN}\end{array}$ & $\begin{array}{c}V_{\text {haunched }} \\
\mathrm{kN}\end{array}$ & $\begin{array}{c}V_{\mathrm{u}} \\
\mathrm{kN}\end{array}$ \\
\hline P1 & 170 & 270 & 0.375 & 379.0 & 217.3 & 434.6 \\
$\mathrm{P} 2$ & 180 & 270 & 0.375 & 432.6 & 254.1 & 508.1 \\
\hline
\end{tabular}

and the steel plate was assumed as steel bars. Finally, the ultimate load was calculated as $V_{\mathrm{u}}=2 V_{\text {haunched. }}$. Table 5 shows some important values during calculation.

4.3. Discussion. In Table 4, the design loads determined according to the specification JTG D62-2004 [15] are presented. $M_{\mathrm{d}}$ is the design moment of midspan section with the width of $1.2 \mathrm{~m} ; V_{\mathrm{d}, \mathrm{fl}}$ is the load when the moment of midspan section reaches $M_{\mathrm{d}}$, and $V_{\mathrm{d}, \mathrm{fl}}=2 M_{\mathrm{d}} / L s ; V_{\mathrm{d}, \mathrm{s}}$ is 2 times of the design shear force of the slab. It can be found that the shear cracking loads for P1 and P2 specimens are 1.91 and 2.35 times as large as the design shear load, respectively. And the shear strengths are 2.35 and 3.59 times as large as the design shear load, respectively. It was confirmed that the positive moment region of the proposed SCC bridge deck slab has enough load-carrying capacities.

The calculated results are summarized in Table 4 and compared with experimental results in Figure 20. For P1 and $\mathrm{P} 2$, the calculation results for shear cracking loads are close to the experimental results. However, since shear stress would be larger due to the discontinuity in geometry in specimens, those simple equations may underestimate the principal tensile stress and overestimate the cracking load.

For shear capacities of P1 and P2 specimens, the calculation results are acceptable. As shown in Table 5, $V_{\text {haunched }}$ for P1 and P2 specimens are $42.7 \%$ and $41.3 \%$ smaller than $V_{c}$, respectively. The unfavourable effect of the haunch on the shear capacities of the positive moment region of SCC bridge deck slab was observed. Therefore, the slope of the haunch from horizontal should be carefully designed.

\section{Results and Discussion of Tests on Negative Moment Region}

\subsection{Test Results}

5.1.1. Failure Modes. As shown in Figure 21, the final cracking states of $\mathrm{N} 1$ and $\mathrm{N} 2$ have been recorded and drawn with the square-dotted grid of $10 \mathrm{~cm}$. In general, the crack spacing is approximately $15 \mathrm{~cm}$. However, more cracks were observed in N1 specimen. This may be due to the fibers used in concrete. In both specimens, shear cracks were caused by the diagonal tension after the deep propagation of the several bending cracks. These cracks initiated at the midheight region of the slab, inclined about $45^{\circ}$, and propagated up to the loading area or the fixed area of the slab and down to the haunch. Then, the shear crack width increased with the displacement load, and the debonding of the steel plate from concrete was observed on the bottom side of the haunch. This action accompanied with the shear cracks and only occurred on the side where shear cracks appeared.

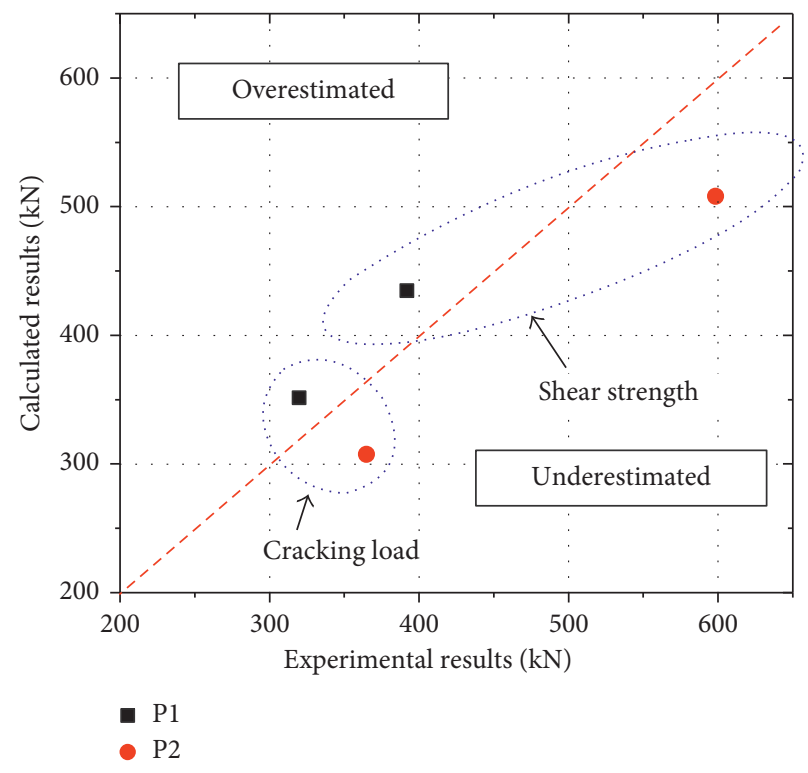

Figure 20: Comparison of experimental and calculated results.

5.1.2. Load-Displacement Relationship. Figure 22 shows the results of the displacement transducers at several loading stages. Sudden change in displacement and large plastic rotation are found at Section B; thus, plastic hinges with large rotation capacities are supposed to form in N1 and N2 specimens.

Figure 23 shows the load-displacement responses of N1 and N2 specimens. The responses are similar, while the loading capacity of N2 is $25 \%$ larger than that of N1. Based on visible monitoring, the flexural cracking loads were $73 \mathrm{kN}$ and $82 \mathrm{kN}$ for $\mathrm{N} 1$ and $\mathrm{N} 2$, respectively. The behavioral difference of two specimens before cracking was small, while it increased afterwards. The load-displacement curve of N1 tends to be flat after the displacement of $30 \mathrm{~mm}$, while the remaining capacity tends to be increasing in that of N2. This observation is consistent with that found in P1 and P2 specimens. The cracking load and ultimate load of the specimens are summarized in Table 6.

5.1.3. Strain Results. Figure 24 shows the results of strain gauges set on the upper layer of the steel bars and on the steel plates. It shows that the strains in the steel bars increased rapidly when the concrete was cracked and reached 2,500 microstrain when the specimens failed. The steel bars had already yielded at that time. However, in the compression region, no. 8 strain gauges in the steel plates show that the steel plate still did not yield in both specimens. Therefore, the loading capacities of the specimen were controlled by the yield strength of the steel bar.

\subsection{Capacity Calculation}

5.2.1. Flexural Cracking Load. When the tensile stress on the top surface of the concrete slab exceeds the concrete flexural strength, flexural cracks form. Then, 


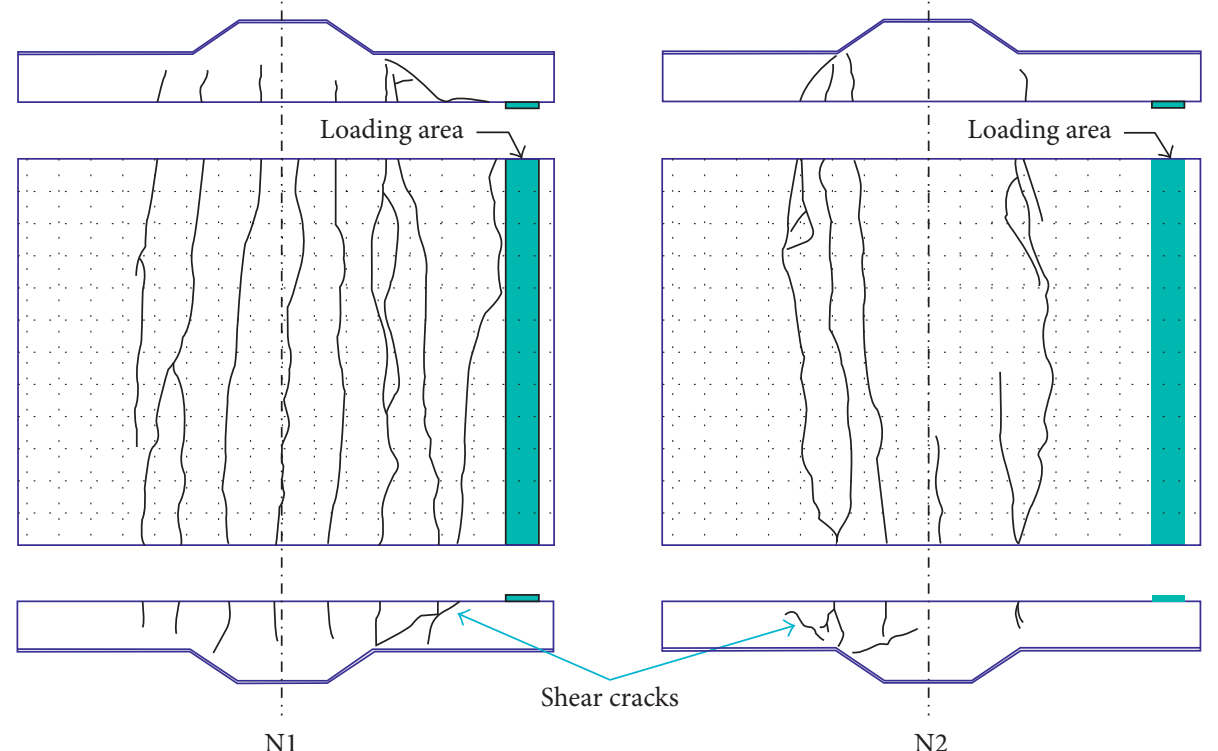

(a)
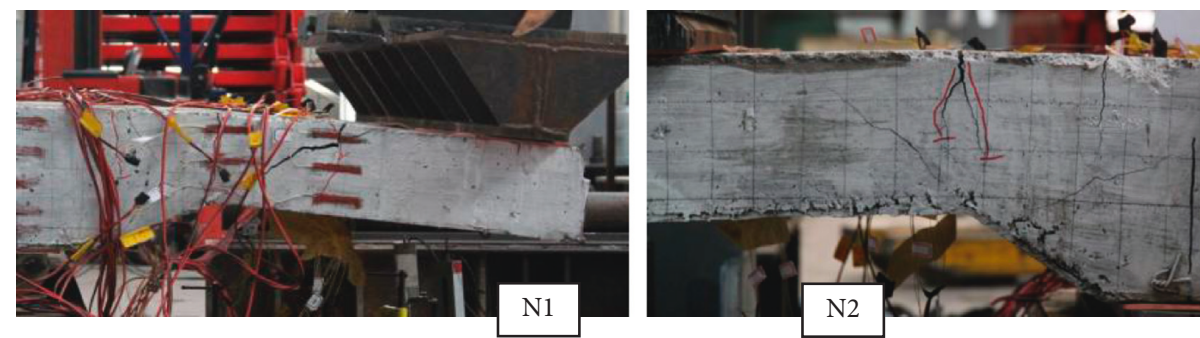

(b)

Figure 21: Cracking modes of N1 and N2 specimens. (a) Crack pattern. (b) Photos of shear cracks.

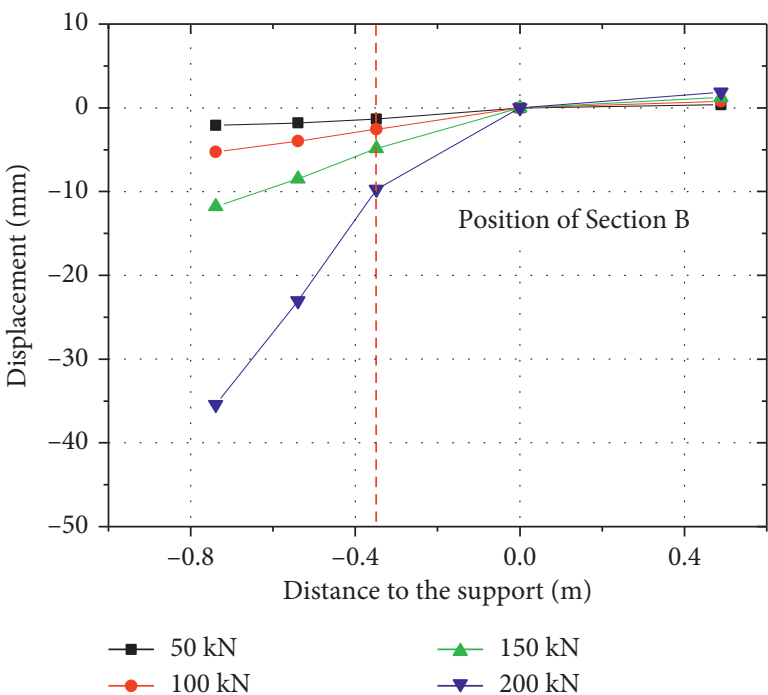

(a)

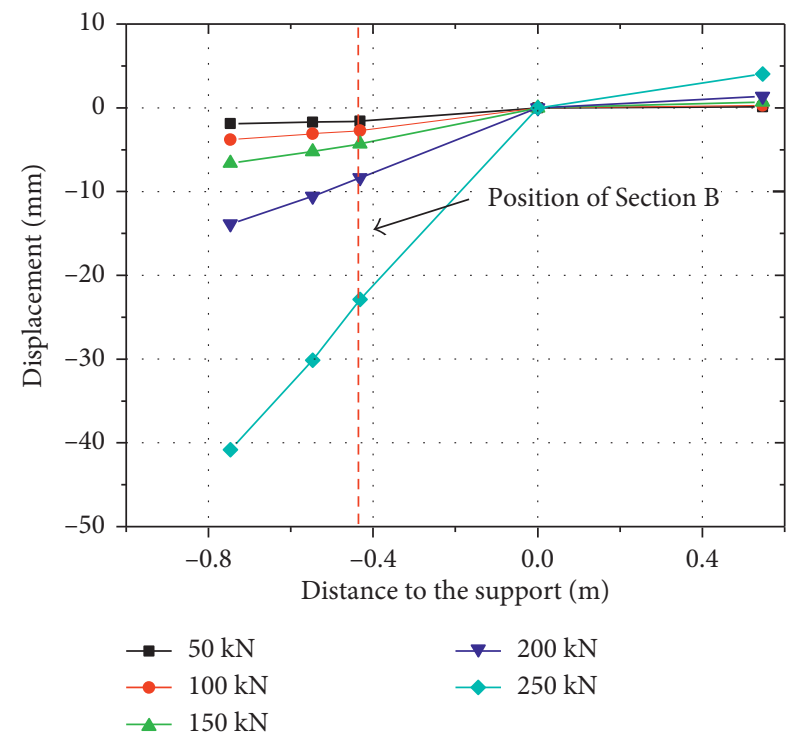

(b)

Figure 22: Deflection along the longitudinal direction of the specimens. 


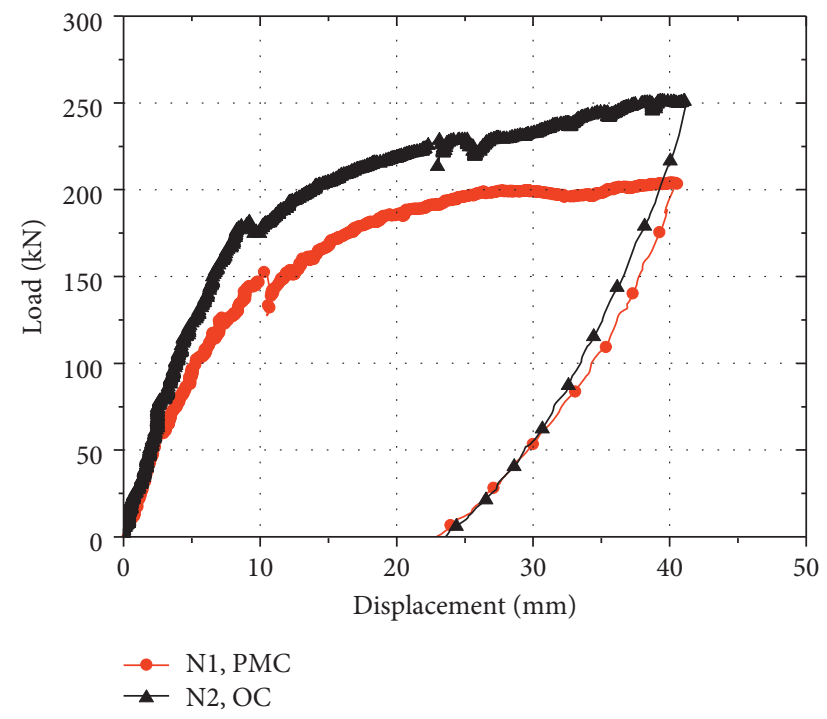

Figure 23: Load-displacement curves of N1 and N2 specimens.

TABLE 6: Comparison of experimental results with the design load and calculated results.

\begin{tabular}{|c|c|c|c|c|c|c|c|c|c|c|c|c|c|c|c|}
\hline & \multicolumn{3}{|c|}{$\begin{array}{l}\text { Experimental } \\
\text { results }\end{array}$} & \multicolumn{3}{|c|}{ Design load } & \multicolumn{3}{|c|}{$\begin{array}{l}\text { Comparison with } \\
\text { design load }\end{array}$} & \multicolumn{3}{|c|}{ Calculated results } & \multicolumn{3}{|c|}{$\begin{array}{l}\text { Comparison with } \\
\text { calculated results }\end{array}$} \\
\hline & $\begin{array}{l}V_{\mathrm{cr}, \mathrm{fl}} \\
(\mathrm{kN})\end{array}$ & $\begin{array}{r}V_{\mathrm{cr}, \mathrm{s}} \\
(\mathrm{kN})\end{array}$ & $\begin{array}{c}V_{\mathrm{u}} \\
(\mathrm{kN})\end{array}$ & $\begin{array}{c}M_{\mathrm{d}} \\
(\mathrm{kN} \cdot \mathrm{m})\end{array}$ & $\begin{array}{l}V_{\mathrm{d}, \mathrm{fl}} \\
(\mathrm{kN})\end{array}$ & $\begin{array}{r}V_{\mathrm{d}, \mathrm{s}} \\
(\mathrm{kN})\end{array}$ & $\eta_{1}$ & $\eta_{2}$ & $\eta_{3}$ & $\begin{array}{c}V_{\text {cr,flCAL }} \\
(\mathrm{kN})\end{array}$ & $\begin{array}{c}V_{\text {cr,sCAL }} \\
(\mathrm{kN})\end{array}$ & $\begin{array}{l}V_{\mathrm{u}, \mathrm{CAL}} \\
(\mathrm{kN})\end{array}$ & $v_{1}$ & $v_{2}$ & $v_{3}$ \\
\hline P1 & 73 & 152 & 204.03 & \multirow{2}{*}{16.0} & \multirow{2}{*}{23.5} & \multirow{2}{*}{96.7} & 0.75 & 1.57 & 2.11 & 74.4 & 147.5 & 194.8 & 1.02 & 0.97 & 0.95 \\
\hline $\mathrm{P} 2$ & 82 & 201 & 251.30 & & & & 0.85 & 2.08 & 2.60 & 71.6 & 163.5 & 215.9 & 0.87 & 0.81 & 0.86 \\
\hline
\end{tabular}

Note. $\eta_{1}=V_{\mathrm{cr}, \mathrm{fl}} / V_{\mathrm{d}, \mathrm{s}} ; \eta_{2}=V_{\mathrm{cr}, \mathrm{s}} / V_{\mathrm{d}, \mathrm{s}} ; \eta_{3}=V_{\mathrm{u}, \mathrm{s}} / V_{\mathrm{d}, \mathrm{s}} ; \nu_{1}=V_{\mathrm{cr}, \mathrm{sCAL}} / V_{\mathrm{cr}, \mathrm{s}} ; \nu_{2}=V_{\mathrm{cr}, \mathrm{flCAL}} / V_{\mathrm{cr}, \mathrm{fl}} ; v_{3}=V_{\mathrm{u}, \mathrm{CAL}} / V_{\mathrm{u}}$.

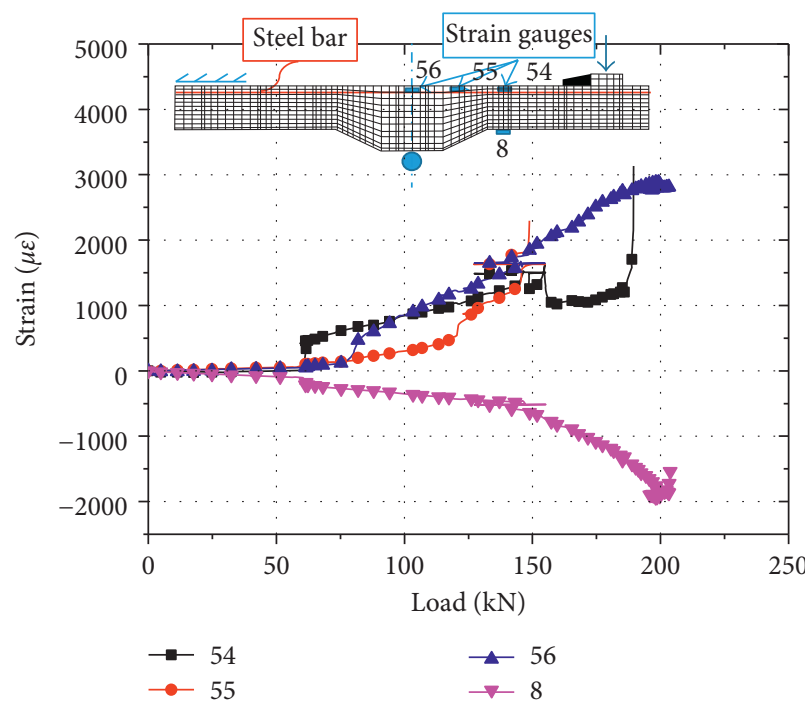

(a)

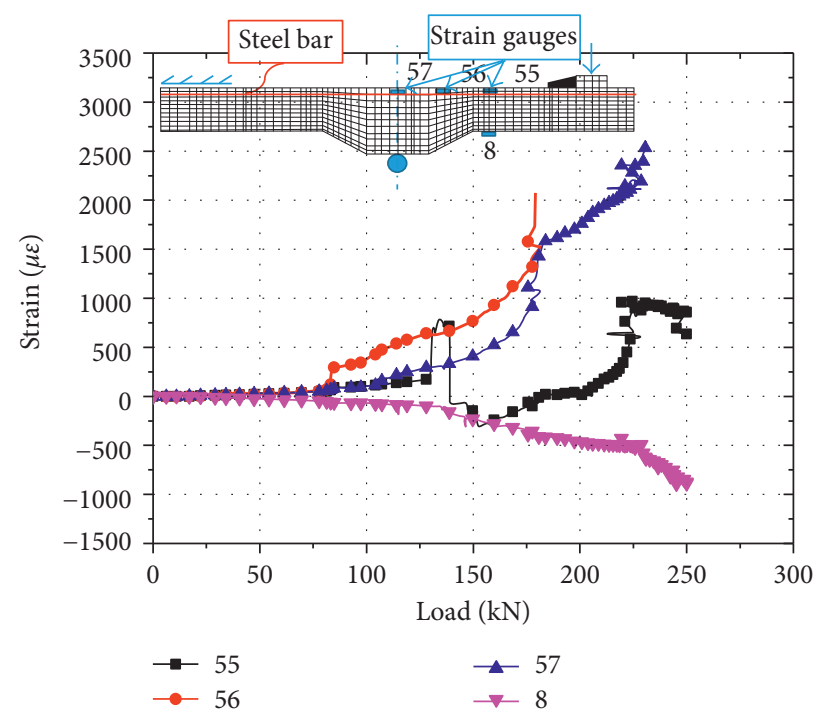

(b)

Figure 24: Strain results of N1 and N2 specimens under different loads. (a) N1. (b) N2. 


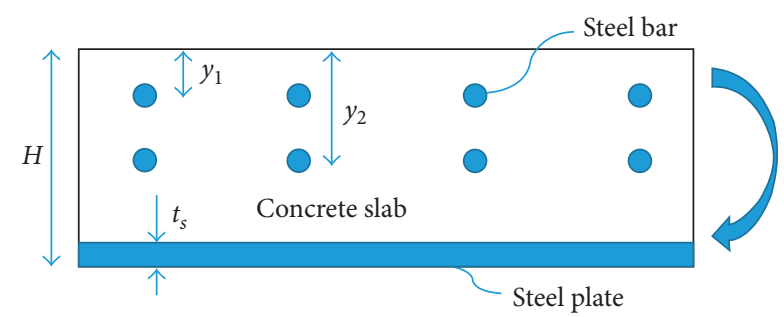

FIgURE 25: Calculation section of the specimen.

$$
f_{\mathrm{ct}, \mathrm{fl}}=\frac{M_{\mathrm{cr}}}{I_{0}} y_{\mathrm{c}} .
$$

The flexural cracking load can be calculated from the cracking moment as

$$
V_{\mathrm{cr}, \mathrm{fl}}=\frac{M_{\mathrm{cr}}}{L}
$$

5.2.2. Shear Cracking Load. The shear forces required to cause the first shear cracks in N1 and N2 specimens were calculated according to [12], which was a semiempirical and semitheoretical equation

$$
V_{\mathrm{cr}, \mathrm{s}}=\left(0.16 \sqrt{f_{\mathrm{c}}^{\prime}}+17 \rho_{\mathrm{s}} \frac{V d}{M}\right) \mathrm{bd} \leq 0.3 f_{\mathrm{c}}^{\prime} \mathrm{bd}
$$

where $\rho_{s}$ is the ratio of rebars and $M$ and $V$ are the bending moment and shear load at the section, respectively.

5.2.3. Flexural Strength. Figure 25 shows the section of the slab. The main assumptions for flexural strength calculation are as follows: (1) the tensile strength of concrete is neglected; (2) the steel plate and concrete slab are completely composited; and (3) steel rebars are stressed to their design yield strength. Then, the position of neutral axis can be determined to be lying inside the steel plate, which means the contribution of the compressed concrete was neglected. Ultimate load was obtained through the moment strength per unit width of the slab which can be simply calculated through only one equation:

$$
M_{\mathrm{u}}=A_{\mathrm{s} 1} f_{\mathrm{y}, r}\left(H-\frac{t_{\mathrm{s}}}{2}-y_{1}\right)+A_{\mathrm{s} 2} f_{\mathrm{y}, \mathrm{r}}\left(H-\frac{t_{\mathrm{s}}}{2}-y_{2}\right),
$$

where $A_{\mathrm{s} 1}$ and $A_{\mathrm{s} 2}$ are the areas of each reinforcing bar layer; $f_{\mathrm{y}, \mathrm{r}}$ is the yield stress of the reinforcing bar; $t_{\mathrm{s}}$ is the thickness of the steel plate; $y_{1}$ and $y_{2}$ are the distances from the center of steel rebars to extreme tension fiber.

The ultimate load can be calculated from the flexural strength as

$$
V_{\mathrm{u}}=\frac{M_{\mathrm{u}}}{L}
$$

\section{Discussion}

In Table 6, the design loads determined according to the specification JTG D62-2004 [15] are presented. It is

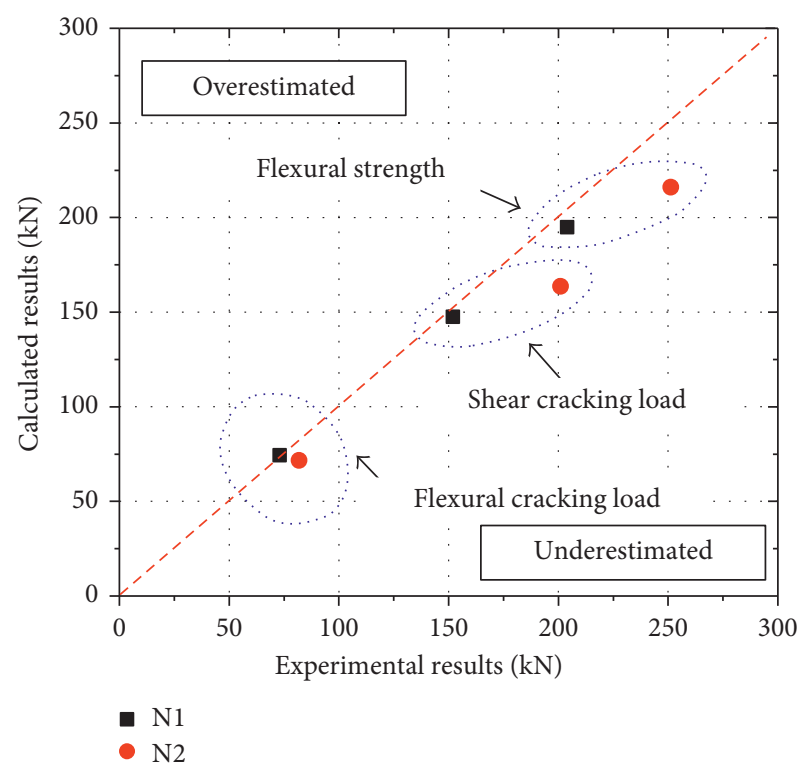

FIGURE 26: Comparison of experimental and calculated results.

observed that the flexural cracking loads of N1 and N2 specimens are little smaller than the design shear load, while the shear cracking loads and ultimate loads are more than 1.5 times as large as the design shear load. Therefore, it can be concluded that the negative moment region of the proposed SCC bridge deck slab has enough load-carrying capacities.

For N1 and N2 specimens, the predicted flexural cracking loads and shear cracking loads were close to the experimental ones, as shown in Figure 26. Meanwhile, the predicted ultimate loads were about 0.9 times as large as experimental ones. The underestimation is because in the experiments, large strains in steel rebars were observed and strain hardening occurred after yielding. In general, the assumptions for calculating load capacities are acceptable.

\section{Conclusions}

An innovative steel and concrete composite bridge deck slab using bent bars and epoxy as shear connectors was proposed. Four specimens of the proposed slab using normal and polymer-mixed concrete were fabricated and tested. The cracking and ultimate loads of the specimens were focused on. The experimental capacities were compared with the calculated ones and the design load. The following conclusions are earned:

(1) Through the comparison of the slab capacities and the design load, it can be concluded that the positive and negative moment regions of the proposed SCC bridge deck slab have enough loadcarrying capacities.

(2) The relative slip between concrete and steel was prevented by the proper arrangement of bent bars and epoxy. As a result, longitudinal shear failure has not occurred in the specimens. 
(3) The design formulae for RC slabs are equivalently applicable to the proposed SCC bridge deck slab. The predicted flexural cracking loads, shear cracking loads, and ultimate loads were close to the experimental ones.

(4) The unfavourable effect of the haunch on the shear capacities of the positive moment region of SCC bridge deck slab was observed. Through the theoretical calculation, it was found that the shear strengths of P1 and P2 specimens were $42.7 \%$ and $41.3 \%$ decreased due to the haunch, respectively.

In summary, the effectiveness of the shear connector design of the proposed SCC bridge deck slab was validated through the tests on four slab specimens. Meanwhile, the effect of haunch on the behavior of the positive moment region of SCC slab was evaluated. Considering the state of the art for composite bridge deck slabs, the authors believe that this study should supply a clue and motive to the future study of this topic.

\section{Conflicts of Interest}

The authors declare that there are no conflicts of interest regarding the publication of this paper.

\section{Acknowledgments}

This study was performed during the first author's academic stay at the Department of Civil Engineering of The University of Tokyo in Japan with the financial support from the China Scholarship Council (CSC). The assistance is gratefully acknowledged.

\section{References}

[1] S. Matsui, Bridge Slabs, Morikita Publishing, Tokyo, Japan, 2007, in Japanese.

[2] S. Matsui, H. Sasaki, Y. Fukumoto, and S. Kajikawa, "Fatigue of steel-concrete composite decks subjected to a moving wheel load," Journal of Structural Engineering, vol. 33, pp. 409-420, 1988, in Japanese.

[3] H. Kaido and S. Matsui, "Evaluation for punching shear fatigue strength of steel plate-concrete composite deck," Journal of Structural Engineering, vol. 64, no. 1, pp. 60-70, 2008, in Japanese.

[4] H. Kaido and S. Matsui, "Evaluation for fatigue strength of shear studs in steel plate-concrete composite deck," Journal of Structural Engineering, vol. 64, no. 4, pp. 765-777, 2008, in Japanese.

[5] H. Y. Kim and Y. J. Jeong, "Experimental investigation on behavior of steel-concrete composite bridge decks with perfobond ribs," Journal of Constructional Steel Research, vol. 62, no. 5, pp. 463-471, 2006.

[6] H. Y. Kim and Y. J. Jeong, "Steel-concrete composite bridge deck slab with profiled sheeting," Journal of Constructional Steel Research, vol. 65, no. 8-9, pp. 1751-1762, 2009.

[7] H. Y. Kim and Y. J. Jeong, "Ultimate strength of a steelconcrete composite bridge deck slab with profiled sheeting," Engineering Structures, vol. 32, no. 2, pp. 534-546, 2010.

[8] C. Fujiyama and K. A. Maekawa, "Computational simulation for the damage mechanism of steel-concrete composite slabs under high cycle fatigue loads," Journal of Advanced Concrete Technology, vol. 9, no. 2, pp. 193-204, 2011.

[9] C. Fujiyama, T. Matsumura, and T. Takasuka, "A failure process of steel-concrete composite bridge deck subjected to repetitive moving loads in three-dimensional nonlinear FE analysis," Journal of JSCE, vol. 70, no. 2, pp. 227-237, 2015.

[10] J. He, Y. Liu, X. Xu et al., "Loading capacity evaluation of composite box girder with corrugated webs and steel tube slab," Structural Engineering and Mechanics, vol. 50, no. 4, pp. 501-524, 2014.

[11] FIB, FIB Model Code 2010-Final Draft, Vol. 1, Bulletins, Lausanne, Switzerland, 2010.

[12] R. Park and T. Paulay, Reinforced Concrete Structures, John Wiley \& Sons, Hoboken, NJ, USA, 1975.

[13] A. Tena-Colunga, H. I. Archundia-Aranda, and Ó. M. González-Cuevas, "Behavior of reinforced concrete haunched beams subjected to static shear loading," Engineering Structures, vol. 30, no. 2, pp. 478-492, 2008.

[14] JSCE-SSCS-2007, Standard Specifications for Concrete Structures, Japan Society of Civil Engineers, Tokyo, Japan, 2007, in Japanese.

[15] Ministry of communication of China, Code for Design of Highway Reinforced Concrete and Prestressed Concrete Bridges and Culverts-JTG D62-2004, China Communications Press, Beijing, China, 2004, in Chinese. 


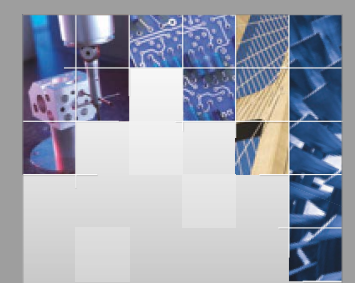

\section{Enfincering}
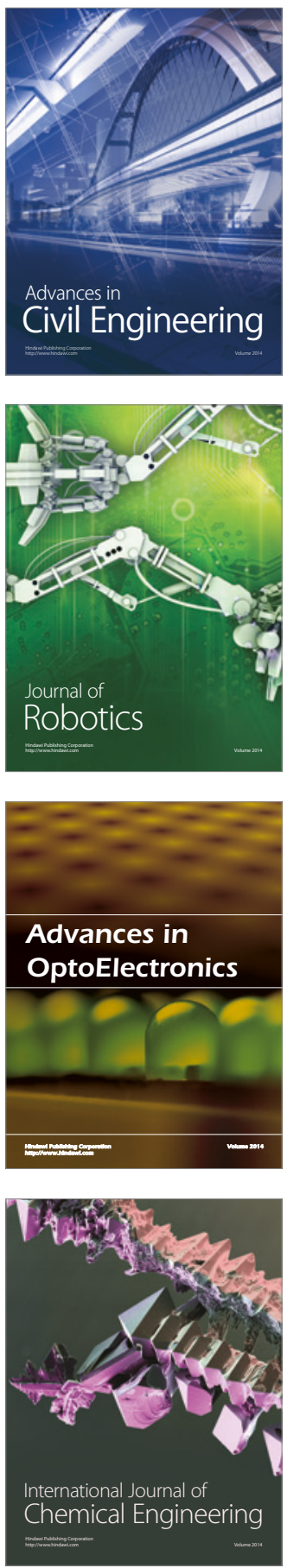

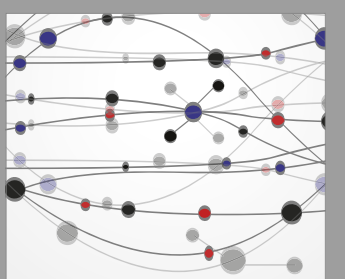

The Scientific World Journal

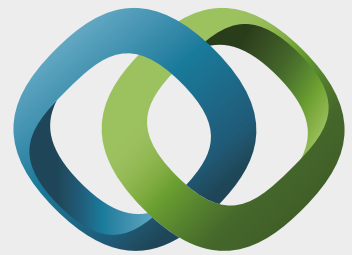

\section{Hindawi}

Submit your manuscripts at

https://www.hindawi.com
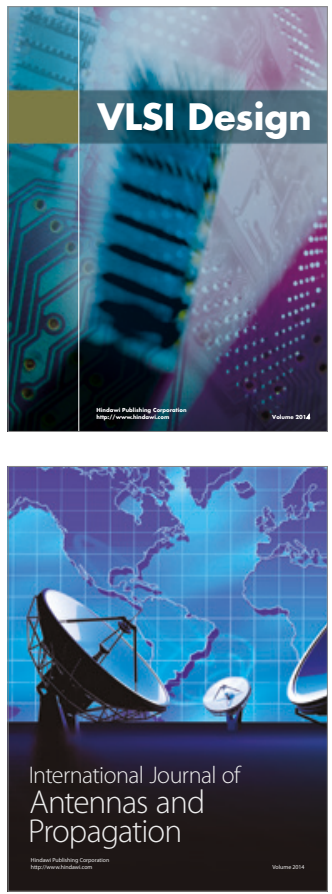

\section{Rotating}

Machinery
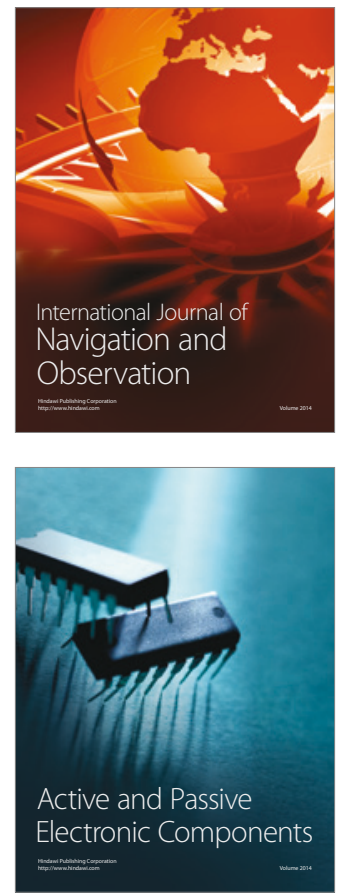
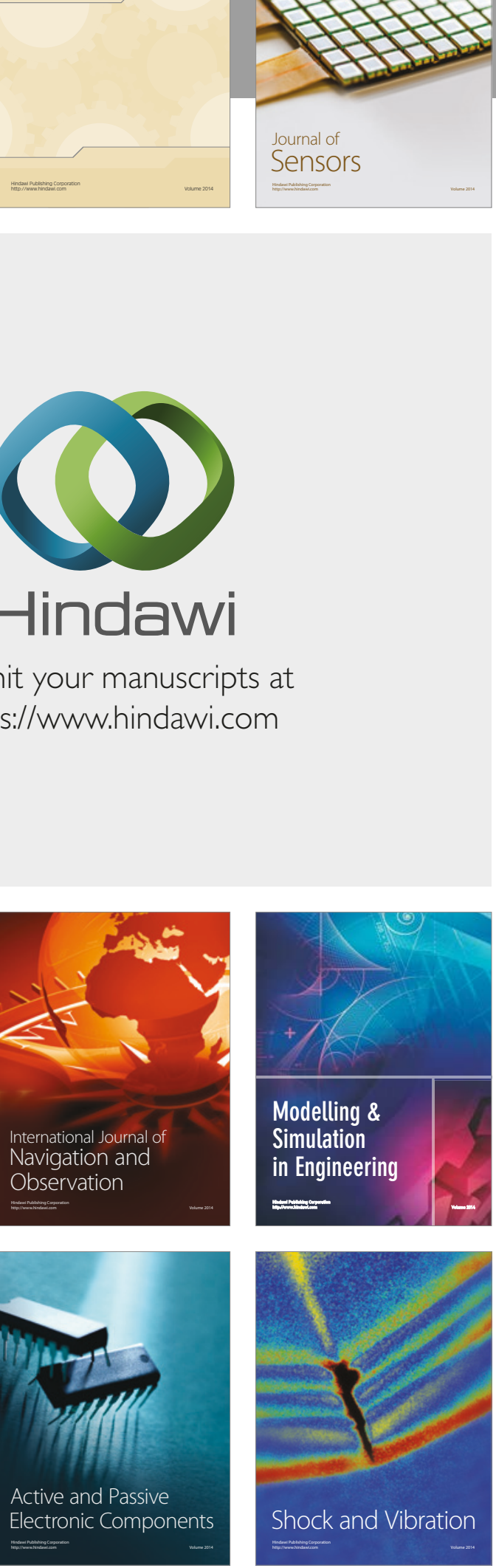
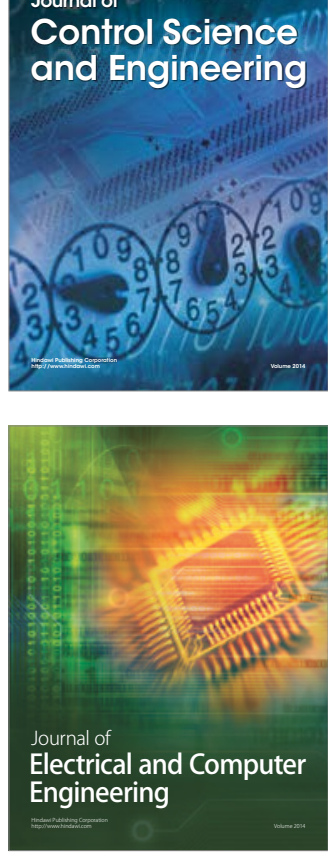

Distributed

Journal of

Control Science

and Engineering
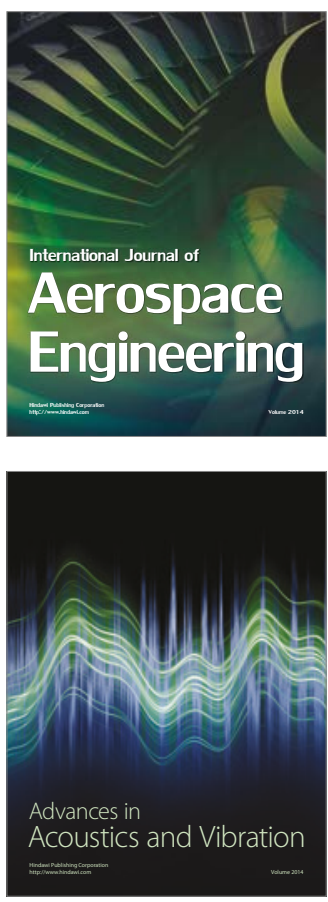

Sensor Networks 